\title{
Physiological Factors Which Influence Cognitive Performance in Military Personnel
}

\author{
Kristy Martin (D), Julien Périard, Ben Rattray iD, and David B. Pyne iD, \\ University of Canberra, Australian Capital Territory, Australia
}

Objective: To identify and detail physiological factors that influence cognition in military personnel.

Background: Maintenance of cognitive and task performance is important under several scenarios, none more so than in a military context. Personnel are prepared for and trained to tolerate many of the stressors they encounter; however, consideration of stressors typically extends only as far as the physical, psychological, and environmental requirements of a given task. While considering these factors certainly characterizes the broader picture, several physiological states and traits can influence cognition and thus, should also be considered.

Method: A systematic review of the electronic databases Medline (PubMed), EMBASE (Scopus), PsycINFO, and Web of Science was conducted from inception up to January 2019. Eligibility criteria included current military personnel, an outcome of cognition, and the assessment of a physiological factor.

Results: The search returned 60,564 records, of which 60 were included in the review. Eleven studies examined the impact of demographic factors on cognition, 16 examined fatigue, 10 investigated nutrition, and 24 the impact of biological factors on cognitive performance.

Conclusion: Factors identified as having a positive impact on cognition include aerobic fitness, nutritional supplementation, and visual acuity. In contrast, factors identified as having a negative impact include fatigue arising from sustained operations, dehydration, undernutrition, and an exaggerated physiological stress response to a cognitive task or a stressor. A further subset of these factors was considered modifiable.

Application: The modifiable factors identified provide avenues for training and preparation to enhance cognition in ways previously unconsidered.

Keywords: soldier, fatigue, cognition, nutrition, decision making

Address correspondence to Kristy Martin, Research Institute for Sport and Exercise, University of Canberra, Building 29, Canberra, Australian Capital Territory 2601, Australia; e-mail: kristy.martin@canberra.edu.au.

\section{HUMAN FACTORS}

Vol. XX, No. X, Month XXXX, pp. 1-31

DOI: $10.1177 / 0018720819841757$

Article reuse guidelines: sagepub.com/journals-permissions Copyright (C) 2019, Human Factors and Ergonomics Society.

\section{INTRODUCTION}

Maintenance of cognitive and task performance is important under several scenarios, none more so than in a military context. Military personnel face particularly unique challenges to cognition, including combinations of extreme physical and mental fatigue, high levels of anxiety and stress, and environments of great unpredictability (Campbell \& Nobel, 2009). The necessity for military personnel to maintain effective cognitive performance in these environments far outweighs that of sedentary or low-risk occupations, with more serious consequences stemming from suboptimal performance. Cognition is required by tasks that demand the sustained focus of attention or concentration, as well as the rapid processing of information. Tasks can require storage, retention, recollection, recognition and manipulation of information, and planning, problem solving, or monitoring of goal-directed behavior. In military personnel, tasks requiring cognition may include conventional surveillance activities, which base detection on monitoring unprocessed sensory input from the environment, as well as computer-generated monitoring tasks associated with the control of missiles, unmanned aerial vehicles, or combat robots. Personnel may also be required to accurately recall the details of an event or operation, or inhibit a response to shoot when a comrade or noncombatant appears during a firefight. Personnel are prepared for and trained to tolerate many of the stressors they may encounter; however, consideration of stressors typically extends only as far as the physical (Knapik, Rieger, Palkoska, Van Camp, \& Darakjy, 2009), psychological (Jha, Stanley, Kiyonaga, Wong, \& Gelfand, 2010), and environmental requirements of a given task (Guo et al., 2016; Radakovic et al., 2007). While considering these factors certainly addresses the primary issues, several physiological states 
and traits can also influence cognition. Thus, in scenarios where cognition is important, the impact of these variables on performance should be considered.

Physiological factors which could influence cognitive performance include aerobic fitness (Colcombe \& Kramer, 2003), nutrition (Lieberman, 2003), age (Deary et al., 2009), and mental fatigue (Lorist, Boksem, \& Ridderinkhof, 2005). While aerobic fitness and nutrition are largely modifiable and can be manipulated to maximize the benefit to performance, age and fatigue are either fixed, or in certain situations unavoidable. Although the detrimental effects of some of these factors are inevitable, greater understanding of their impact on performance allows any potential decrement to be addressed. More targeted research should identify characteristics which may make an individual more resilient to a range of different physiological stressors. The aim of this systematic review was to identify and detail individual physiological states and traits that influence cognition, either positively or negatively, focusing specifically on studies utilizing military personnel. We will discuss these identified factors and demonstrate how they may be manipulated to promote resilient cognition. By identifying these factors, negative influences may be countered or managed where possible, and factors that have a positive effect on cognition promoted and encouraged. This information will assist in the development and evaluation of strategies and training programs to enhance cognitive and military task performance.

\section{METHOD}

\section{Search Strategy}

To direct the design of the search strategy, two systematic reviews (Buckman et al., 2011; Calabrese et al., 2007) were consulted and search terms piloted to identify potential articles for inclusion in the review. A search of Medline (PubMed), EMBASE (Scopus), PsycINFO, and Web of Science was then conducted up to January 2019, using medical subject headings (MeSH) for "mental processes" and "military personnel" searched in "All Fields." The MeSH term mental processes incorporates the search terms cognition, executive function, learning, and perception, among others. The MeSH term military personnel also incorporates several search terms including army, coast guard, navy, sailors, air force, submariners, and soldiers.

\section{Inclusion and Exclusion Criteria}

Studies were included from the initial review of articles if they met the following criteria: (a) included current military personnel without injury (e.g., traumatic brain injury), neurological condition (e.g., stroke), or mental illness (e.g., depression, post-traumatic stress disorder) which may have affected the cognitive performance of the participant; (b) assessed at least one outcome of cognition or military task performance requiring a substantial cognitive component; (c) the study assessed the impact of a physiological state or trait on cognitive or military task performance; and (d) where appropriate, the study included either a control group or a baseline measure of performance. For the current review, cognitive performance was classified according to previously described cognitive domains (Lezak, Howieson, \& Loring, 2004). The domains considered were attention and processing speed (the sustained focus of cognitive resources with selective concentration and rapid processing of information), working memory (shortterm storage and manipulation of information), declarative memory (retention, recollection, and recognition of previously encountered information), and executive function (a set of cognitive skills responsible for the planning, initiation, sequencing, and monitoring of complex, goal-directed behavior). The performance of a military task was also included in the review if the task required aspects of these cognitive domains, for example, marksmanship, where the participant was required to detect, identify, and fire at an appropriate target. The physiological factors included in the review were largely individual characteristics, considered as traits, or the physiological condition of an individual at a given time, considered a state. Traits remain generally unchanged within an individual, such as sex and visual acuity, whereas an individual's state can fluctuate over time and may include being physically fatigued or dehydrated. Studies were excluded if they reported in a language other than English or 
if they were not published original research. The impact of the ingestion of pharmaceutical agents, including caffeine, was considered outside the scope of this review and studies of this nature were excluded. Furthermore, studies which included aspects of sleep deprivation or sleep restriction were also deemed outside the scope of this review and readers are directed to recent reviews on this topic (Harrison \& Horne, 2000; Lim \& Dinges, 2010).

\section{Quality Assessment}

The Physiotherapy Evidence Database (PEDro) scale was used to assess study quality (Sherratt \& Hersh, 2010). For the present review, only eight of the 11 items on the scale were considered appropriate. These items included the following: whether the eligibility criteria for participants had been specified; whether the allocation of participants to groups or order of intervention was randomized; whether, where possible, the participant, researcher, and/or assessor was blinded; whether a key outcome measure was obtained for more than $85 \%$ of participants; whether a between-group statistical comparison was reported for at least one key outcome; and whether the study reported both point measures and measures of variability. Items were scored by the lead author as either present (1), absent (0), or not applicable (NA) and a total score out of 8 was obtained by summation.

\section{RESULTS AND DISCUSSION}

\section{Study Selection}

The flow of records through the review process is summarized in Figure 1. The initial search strategy returned 60,564 records, of which 55,243 were excluded due to nonrelevance of titles. A total of 158 articles were retrieved for full-text review, of which 60 articles were selected based on the inclusion criteria. To assist with reporting, the selected studies were grouped into four themes. The themes included demographic factors $(n=11)$, fatigue $(n=16)$, nutritional status $(n=10)$, and biological factors $(n=24)$. One study examined both demographic and biological factors separately and is reported in both themes.

\section{Quality Assessment}

The quality assessment of each study is detailed in Online Resource 1 (available with the manuscript on the $H F$ website). Quality assessment was conducted using a modified version of the PEDro scale with studies scoring between 1 and 7 out of a possible 8 points. Given the variable being examined, or the experimental design, many of the studies did not, or could not, randomly allocate participants to groups, or the order of conditions. Similarly, few studies could blind both participants and researchers to the conditions. A further limitation of several studies was the failure to obtain a measure of at least one key outcome for more than $85 \%$ of the participants initially allocated to groups.

\section{Demographic Factors}

Ten studies investigated the effect of demographic factors on cognitive and military task performance. An overview of these studies is presented in Table 1. Four studies investigated the effect of age on cognitive performance, while nine compared performance for sex differences. In each of the studies, participants were male or female military personnel or active duty soldiers. The age groups ranged from $17-20$ to $56-65$ years.

Age. Performance across the cognitive domains tended to decline with advancing age. This effect was particularly true for response speed, although measures of accuracy were reported to be improved, unaffected, and impaired by increasing age. On tasks of attention and processing speed, simple reaction time (Roebuck-Spencer et al., 2008; Vincent et al., 2008; Vincent, Roebuck-Spencer, Gilliland, \& Schlegel, 2012), choice reaction time (Vincent, Roebuck-Spencer, Gilliland, \& Schlegel, 2012), and reaction time on a continuous performance task (Roebuck-Spencer et al., 2008; Vincent et al., 2008) largely deteriorated with increasing age. The average magnitude of change from the youngest (17-25 years) to the oldest (30-65 years) age group was $9 \%, 14 \%$, and $18 \%$ respectively. A similar trend was observed for tasks of working memory, with reaction time $24 \%$ slower in participants aged 30 to 65 years, compared 


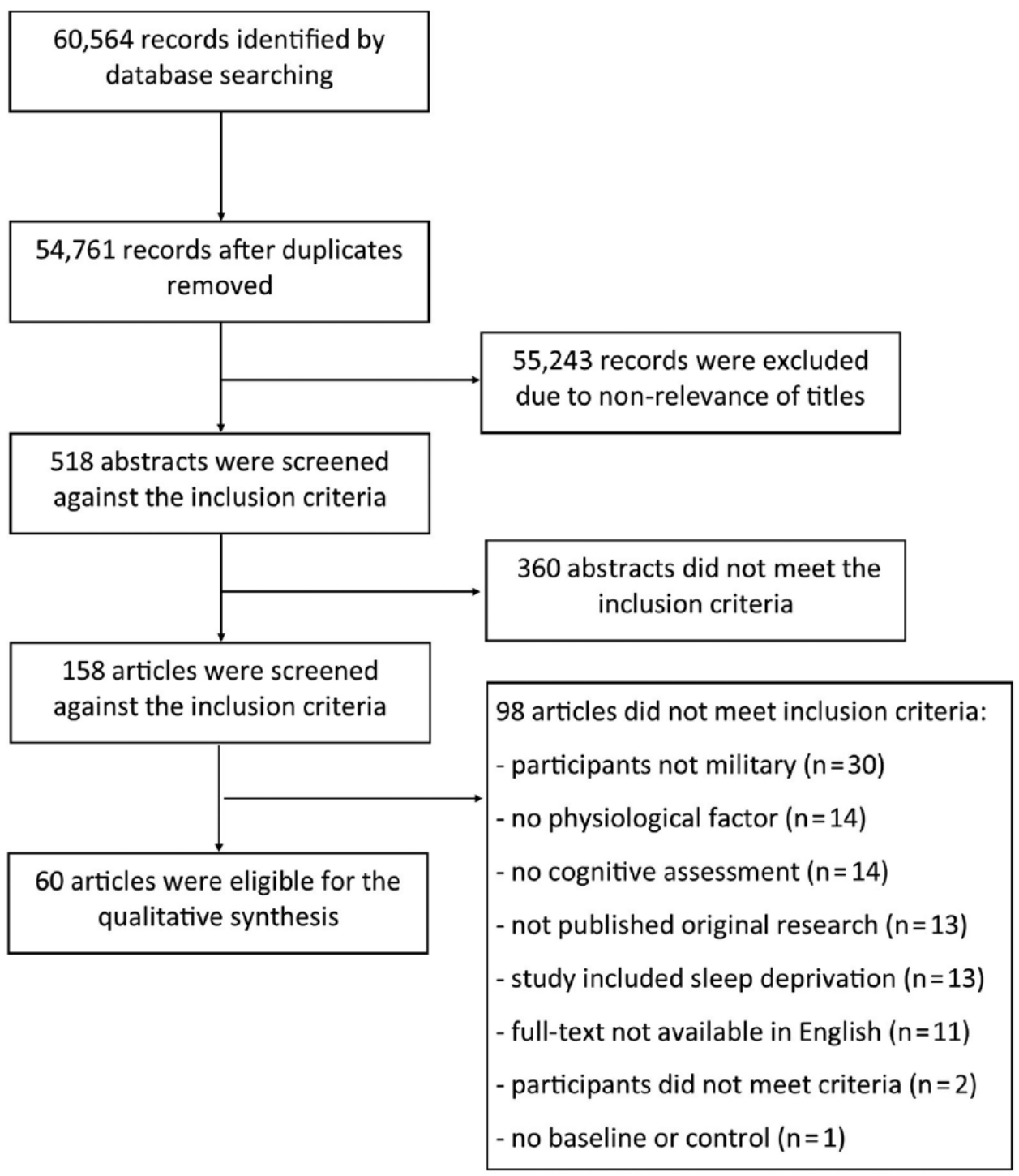

Figure 1. Flow diagram of the process of study selection, including reason for exclusion at the full-text stage.

with 17 to 25 years (Roebuck-Spencer et al., 2008; Vincent et al., 2008; Vincent, RoebuckSpencer, Gilliland, \& Schlegel, 2012). Accuracy on a choice reaction time task was marginally improved (1\%) from 17-20 to 56-65 years (Vincent, Roebuck-Spencer, Gilliland, \& Schlegel, 2012), while accuracy on a continuous performance task was unaffected (Roebuck-Spencer et al., 2008; Vincent et al., 2008). For tasks of working memory, accuracy was variously reported as worse (Vincent et al., 2008; Vincent,
Roebuck-Spencer, Gilliland, \& Schlegel, 2012), unaffected (Roebuck-Spencer et al., 2008), or marginally improved (Vincent, RoebuckSpencer, Gilliland, \& Schlegel, 2012).

The impact of age on cognitive performance was like that observed in a civilian cohort, with increasingly poorer performance after the mid30s (Heaton, Ryan, Grant, \& Matthews, 1996). Verbal skills and well-learned information are thought to hold up best, while perceptual and psychomotor skills decline more markedly 


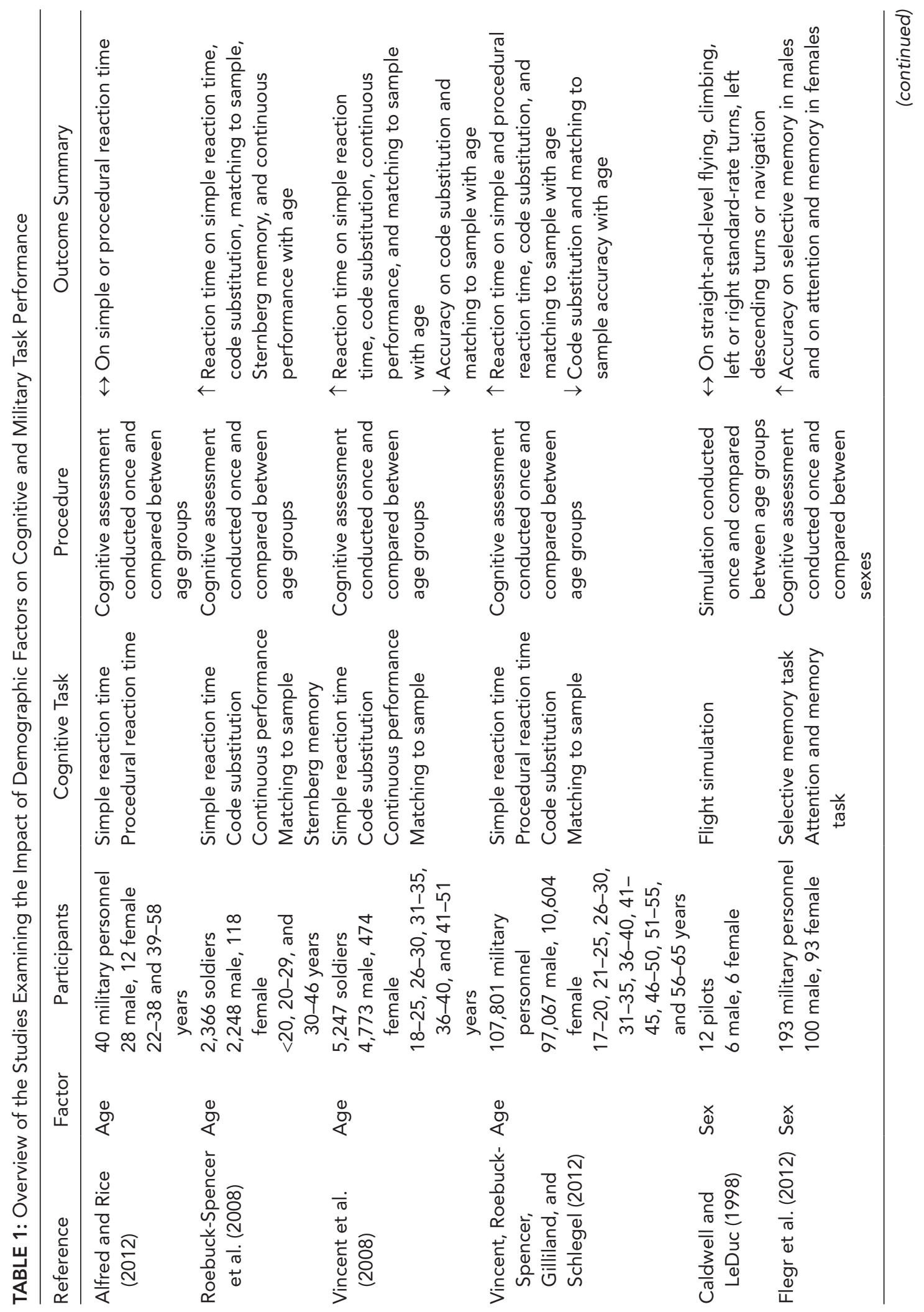




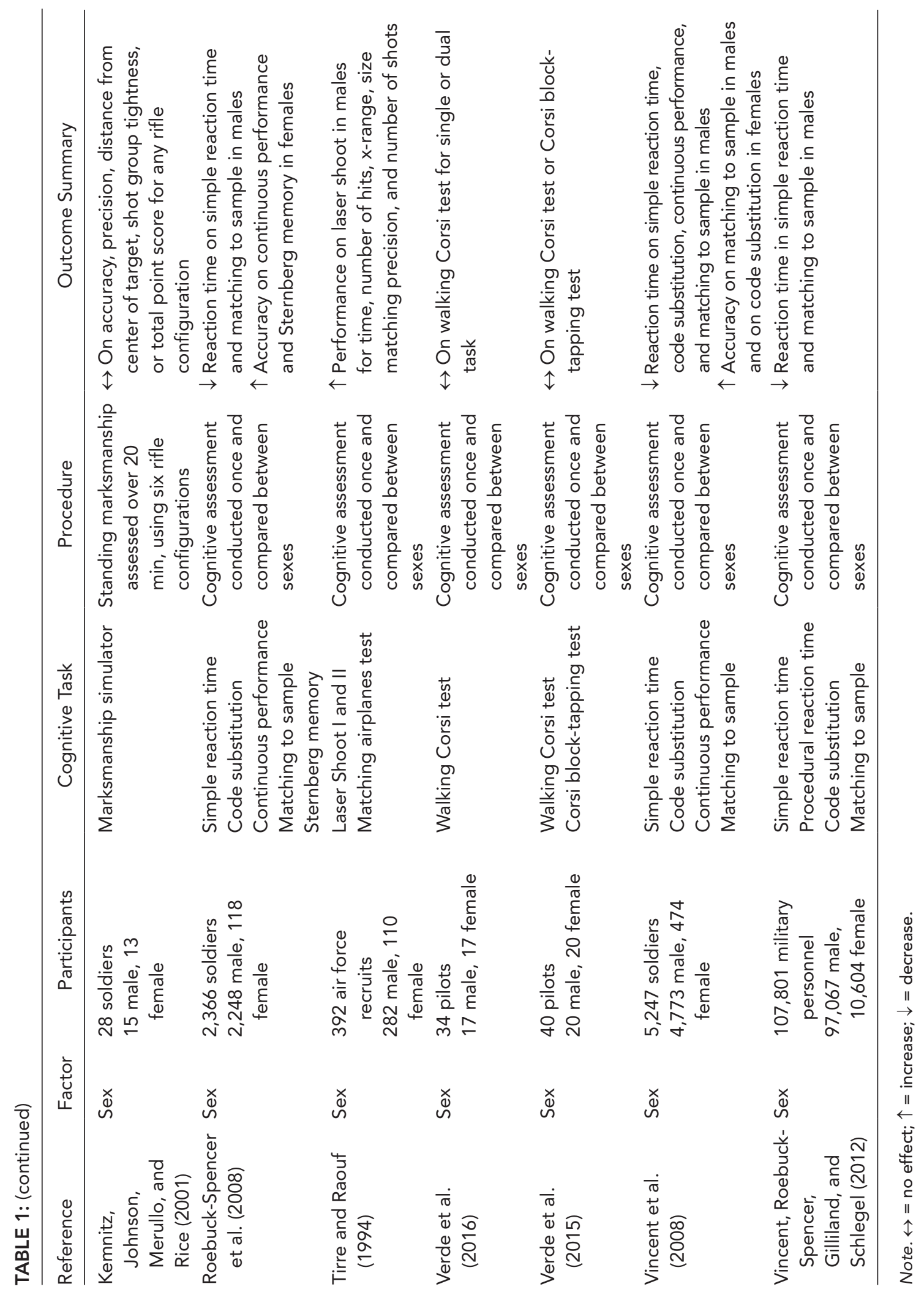


(Leckliter \& Matarazzo, 1989). While aging is inevitable, and several factors can moderate the impact of age on cognition (Colcombe et al., 2003; Seeman, Lusignolo, Albert, \& Berkman, 2001 ), in an aging workforce ongoing monitoring of cognitive ability is needed to ensure high performance is maintained, particularly on tasks requiring rapid responses.

Sex. Like age, the impact of sex on cognition was more consistent for reaction time than accuracy. For tasks of attention and processing speed, males recorded faster response speeds for simple reaction time (Roebuck-Spencer et al., 2008; Vincent et al., 2008; Vincent, Roebuck-Spencer, Gilliland, \& Schlegel, 2012) and one version of a continuous performance task (Vincent et al., 2008). For choice reaction time (Vincent et al., 2008) and the other version of a continuous performance task (Roebuck-Spencer et al., 2008), there was little difference between sexes. In one instance, accuracy on the continuous performance task was greater in females (RoebuckSpencer et al., 2008), in the other instance no difference was reported (Vincent et al., 2008). For tasks of working memory, males recorded faster reaction times on the matching to sample task (Roebuck-Spencer et al., 2008; Vincent et al., 2008; Vincent, Roebuck-Spencer, Gilliland, \& Schlegel, 2012), but not any of the other working memory tasks (Flegr et al., 2012; Roebuck-Spencer et al., 2008; Verde et al., 2016; Verde et al., 2015; Vincent et al., 2008; Vincent, Roebuck-Spencer, Gilliland, \& Schlegel, 2012). Sex mostly had no effect on accuracy on tasks of working memory (Roebuck-Spencer et al., 2008; Verde et al., 2016; Verde et al., 2015; Vincent et al., 2008; Vincent, Roebuck-Spencer, Gilliland, \& Schlegel, 2012), although males outperformed females on a selective memory (Flegr et al., 2012), matching to sample (Vincent et al., 2008), and a code substitution delayed task (Vincent et al., 2008). Females were marginally more accurate on a code substitution task (Vincent et al., 2008) and the Sternberg memory paradigm (Roebuck-Spencer et al., 2008). Although males tended to respond faster than females on several cognitive tasks, a speedaccuracy trade-off was not apparent. For three of the four tasks showing faster response time in males, accuracy was no different to females. For the fourth task, a task of working memory, males recorded superior reaction times and accuracy.

Sex did not affect performance on military tasks in which participants were well-trained. There was no difference between males and females for marksmanship (Kemnitz, Johnson, Merullo, \& Rice, 2001) or flight simulation (Caldwell \& LeDuc, 1998). On a novel visual perceptual-motor task, where participants were required to either shoot at, or from an aircraft, and match aircrafts in space, males performed better than females, although the difference between sexes was small (Tirre \& Raouf, 1994). In research outside of the military, males tend to outperform females on psychomotor tasks (Avolio \& Waldman, 1994) and tasks of visual spatial ability (Weiss, Kemmler, Deisenhammer, Fleischhacker, \& Delazer, 2003). Several studies have reported an interaction between training and sex on performance of these tasks such that extended practice benefits females more than males, consequently reducing or eliminating initial differences in performance (Chance \& Goldstein, 1971; J. M. Connor, Serbin, \& Schakman, 1977; Goldstein \& Chance, 1965). While these findings indicate there are some sex differences in performance on cognitive and military tasks, it is important to recognize that group differences are small and may have little practical applicability.

\section{Fatigue}

Sixteen studies investigated the effect of fatigue on cognitive and military task performance. An overview of these studies is presented in Table 2. In this review, fatigue was considered as a multifaceted construct arising from several isolated and combined sources. This definition includes acute physical and mental fatigue resulting from a single bout of physical or mental exertion, as well as fatigue arising from the performance of sustained military activities or training courses which may place physical, mental, and/or emotional demands on personnel. We also include chronic fatigue accumulated over longer periods of time, such as basic combat training or deployment. Ten studies investigated the effect of acute physical or mental fatigue on cognitive performance, two studies utilized sustained military activities, and 


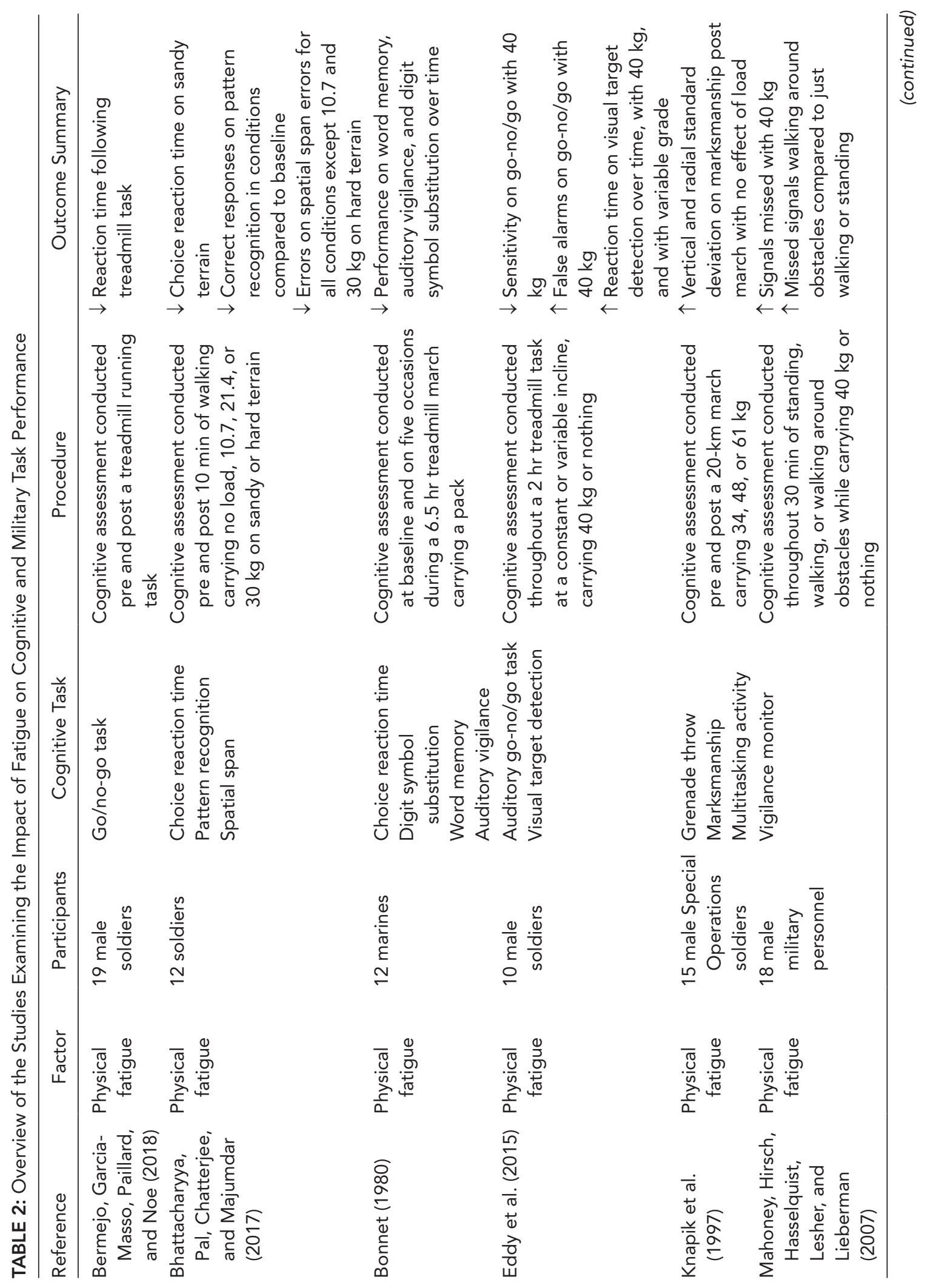




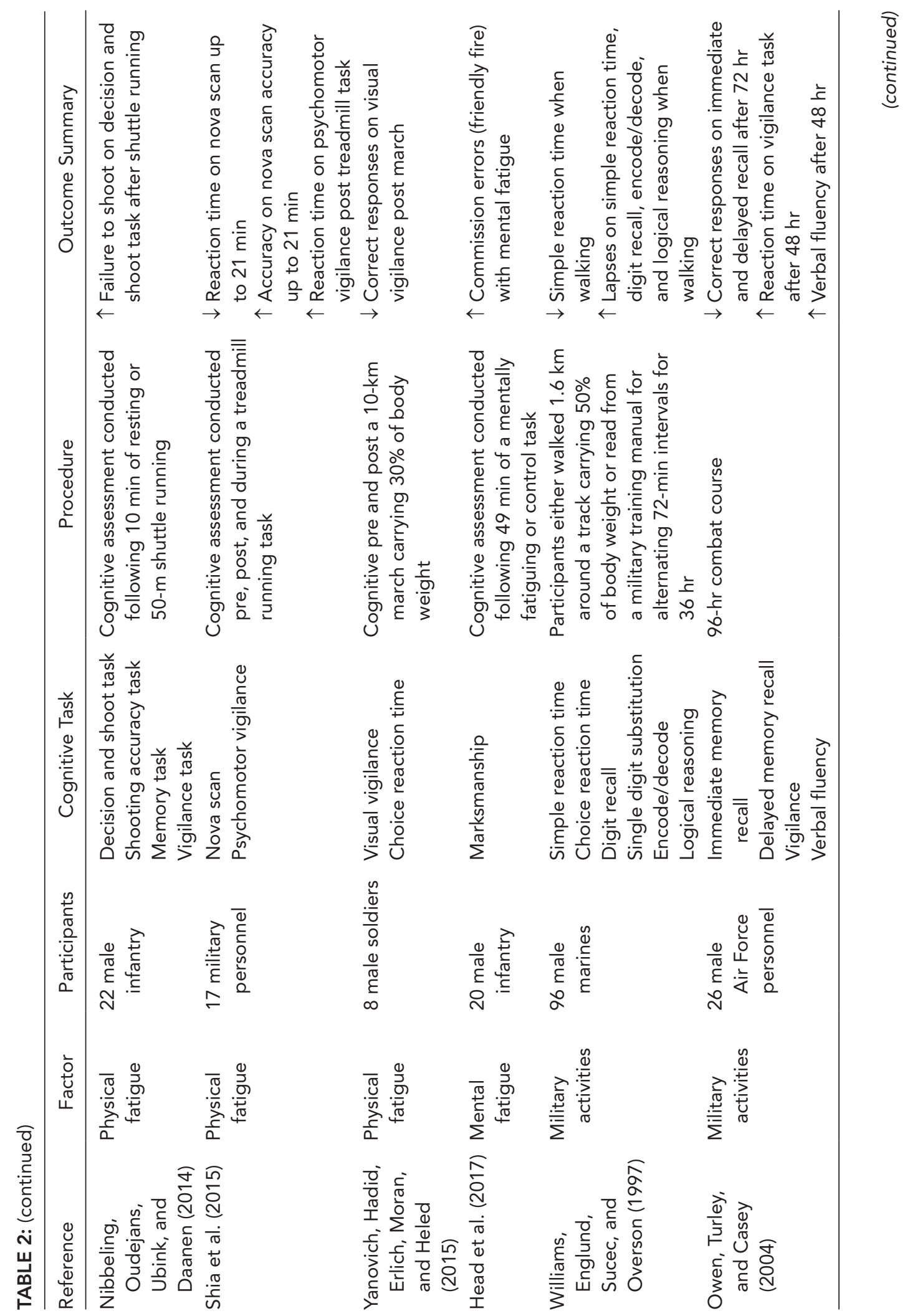




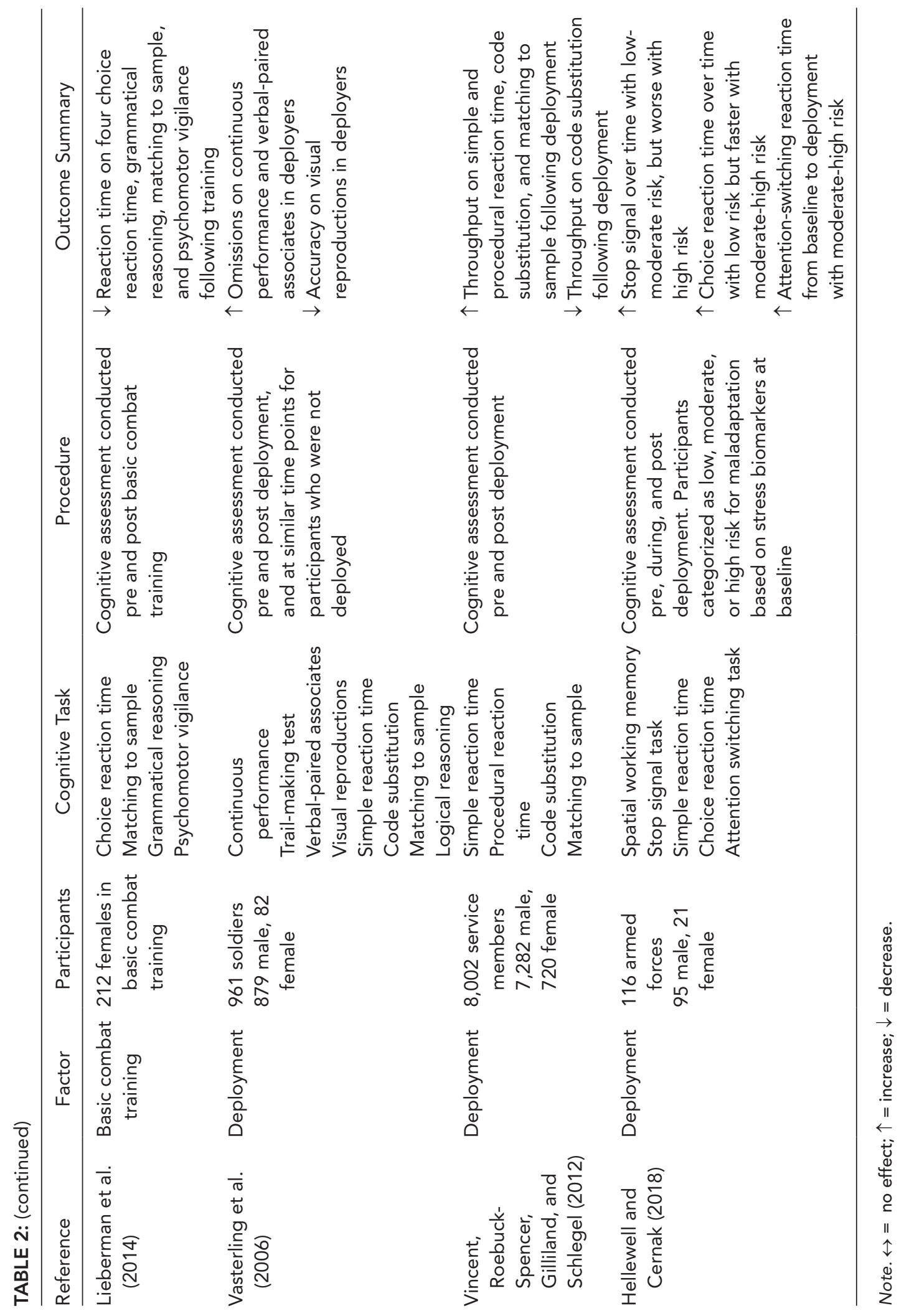


four studies examined chronic fatigue under scenarios of basic combat training or deployment. Participants were described by terms including soldiers, air force personnel, and special operation soldiers. Most of the studies used male participants, with only one study specifically examining the effect of fatigue on females.

Acute fatigue. The impact of acute physical fatigue on cognitive performance appeared to be related to an interaction between the duration of the fatiguing task and the task intensity or load. Shorter duration tasks had little impact on performance. Ten minutes of shuttle running had no effect on vigilance, working memory, or marksmanship (Nibbeling, Oudejans, Ubink, \& Daanen, 2014), and 10 min of loaded walking did not consistently impact choice reaction time or working memory (Bhattacharyya, Pal, Chatterjee, \& Majumdar, 2017). Likewise, a 10-km walk carrying $30 \%$ of total body mass did not affect choice reaction time or a vigilance task (Yanovich, Hadid, Erlich, Moran, \& Heled, 2015). In a recent meta-analysis, acute physical activity was reported to improve cognition when intensity is light to moderate, but when the activity is reported as hard to maximal, no benefit is observed (Chang, Labban, Gapin, \& Etnier, 2012). Working memory accuracy was facilitated by physical exertion for the first $21 \mathrm{~min}$ of an incremental treadmill protocol, after which there was no difference to baseline (Shia et al., 2015). Pre to post the treadmill protocol, reaction time on a vigilance task was $6 \%$ slower (Shia et al., 2015), as well as 7\% slower following a 2-hr treadmill march (Eddy et al., 2015). Following a $6.5-\mathrm{hr}$ treadmill march, working memory accuracy was $7 \%$ worse and sensitivity on a vigilance task, calculated as $z$ (hit rate) $-z$ (false alarm rate), was $\sim 20 \%$ lower (Bonnet, 1980).

Increasing the intensity of the physical task by increasing physical load also impaired cognitive performance. Reaction time on a vigilance task was $4 \%$ slower, and there was a $9 \%$ increase in the proportion of false alarms when participants completed a loaded $(40 \mathrm{~kg})$ compared with unloaded treadmill march (Eddy et al., 2015). Similarly, a greater number of signals were missed during a vigilance task when carrying 40 $\mathrm{kg}$, compared with carrying nothing, and while walking around obstacles, compared with walking unobstructed or standing (Mahoney, Hirsch, Hasselquist, Lesher, \& Lieberman, 2007). A $20-\mathrm{km}$ road march carrying between 34 and $61 \mathrm{~kg}$ increased marksmanship variability but had no impact on a grenade throw (Knapik et al., 1997).

Although the impact of acute physical fatigue on cognitive performance was largely consistent when considering task duration and load, it must be noted that fitness level can moderate the impact of physical activity on cognition with positive effects evident for highly fit individuals, and negative effects in those of low fitness (Chang et al., 2012). Indeed, a moderating effect of fitness may explain the unaffected performance of special operations soldiers on a task of executive function when completing a $20-\mathrm{km}$ road march while carrying loads of 34 to $61 \mathrm{~kg}$ (Knapik et al., 1997). In contrast, performance on a task of executive function was worse when regular soldiers were required to carry $40 \mathrm{~kg}$ while walking on a treadmill for $2 \mathrm{hr}$ (Eddy et al., 2015).

Only one study examined the effect of acute mental fatigue on military performance; however, given the increasing cognitive demand on a soldier, it is imperative to consider how fatigue arising from mental exertion impacts performance. Performing a demanding cognitive task for $49 \mathrm{~min}$ did not affect reaction time or overall accuracy on a marksmanship task, but participants were $16 \%$ more likely to shoot when they should have withheld (Head et al., 2017). Mental fatigue is also known to affect cognitive processes more widely, including flexibility, planning, and performance monitoring (Lorist et al., 2005; Van der Linden, Frese, \& Meijman, 2003). Mental fatigue impairs physical endurance performance, increasing perception of effort at a given workload (Van Cutsem et al., 2017). Several pharmaceutical agents, including caffeine and modafinil, have been used to try and mitigate the effects of mental fatigue on performance, although many have undesirable side effects, particularly in relation to subsequent sleep (Buguet, Montmayeur, Pigeau, \& Naitoh, 1995; James, 1998). Identifying individual characteristics, behaviors, or interventions which reduce an individual's susceptibility to fatigue would therefore be useful. 
Sustained military activities. Combined physical and mental fatigue arising from sustained military activities was largely detrimental to cognitive performance. Thirty-six hours of intermittent walking while carrying a heavy backpack increased simple reaction time by $10 \%$ and the number of lapses (excessively long responses) by 11\% (Williams, Englund, Sucec, \& Overson, 1997). The intermittent walking had no impact on reaction time or overall accuracy on a digit recall task but increased the number of lapses by $138 \%$ (Williams et al., 1997). The number of lapses on a logical reasoning and a decoding task was also increased by $10 \%$ and $9 \%$ respectively, across the $36 \mathrm{hr}$ (Williams et al., 1997). Over the course of a 96-hr combat course, reaction time on a vigilance task was slower by an average of 17\% (Owen, Turley, \& Casey, 2004). The number of correct responses on an immediate recall task was also reduced by $18 \%$, and by $28 \%$ on a delayed recall task (Owen et al., 2004). In contrast, verbal fluency was improved after $48 \mathrm{hr}$, but was no different to baseline thereafter (Owen et al., 2004).

During sustained military activities, cognitive performance tends to worsen as duration increases. During these activities, however, personnel can face multiple stressors which make it difficult to determine the contribution of individual stressors to performance. Although difficult to design, future research should attempt to isolate the various stressors, controlling for confounding variables. A greater understanding of the level of contribution of each stress to performance would allow for a more targeted approach in the development of potential mitigation strategies.

Chronic fatigue. Deployment appeared to have little impact on cognition. Performance was improved, unchanged, and impaired across cognitive domains, with all reported changes marginal. One study specially examined individual characteristics which may predict those more at risk of impaired performance over a period of deployment (Hellewell \& Cernak, 2018). This study assessed biological markers of stress including cortisol, testosterone, and $\alpha$ amylase, as well as parameters of immunity and inflammation. Although the effect of these biomarkers on performance will be discussed in the
"Biological Factors" section, it may be possible to predict individuals more susceptible to performance decline by examining early signs of stress maladaptation. On tasks of attention and processing speed, simple and choice reaction time was improved by an average of $4 \%$ across deployment in one study (Vincent, RoebuckSpencer, Lopez, et al., 2012), but was impaired or unchanged in another, which evaluated the stress-related biomarkers present just prior to deployment (Hellewell \& Cernak, 2018). For simple reaction time, the performance of personnel who exhibited one or fewer stress-related biomarkers was marginally slower during deployment compared with pre-deployment. The performance of personnel who exhibited two or more stress-related biomarkers was unchanged. For choice reaction time, all personnel recorded slower reaction time during deployment (Hellewell \& Cernak, 2018). For tasks of working memory, performance on a matching to sample (Vincent, Roebuck-Spencer, Lopez, et al., 2012) and spatial working memory task (Hellewell \& Cernak, 2018) was improved pre to post deployment, although the magnitude of effect ranged from trivial to small. An $8 \%$ greater decline over time was observed in deployers compared with non-deployers on a visual reproduction task (Vasterling et al., 2006), and on a paired associates task an $11 \%$ greater improvement was recorded in the non-deployers (Vasterling et al., 2006). On tasks of executive function, logical reasoning did not differ over time in deployers compared with non-deployers (Vasterling et al., 2006), while in individuals at a low to moderate risk of stress maladaptation response inhibition improved from baseline to deployment but became impaired in those at high risk (Hellewell \& Cernak, 2018).

In contrast to deployment, basic combat training had a largely consistent impact on cognition. The physically and psychologically stressful process of transitioning from civilian to military life is seemingly beneficial, rather than detrimental to cognitive performance. In over 100 female cadets, 12 weeks of basic combat training improved choice reaction time by $3 \%$, and reaction time on a vigilance task by $5 \%$ without any change in accuracy (Lieberman et al., 2014). Reaction time on a working 
memory task was also improved by $5 \%$, with a $2 \%$ increase in correct responses (Lieberman et al., 2014). Dedicated physical and cognitive training programs can be effective in improving cognition across different cohorts (Ardoy et al., 2014; Ball et al., 2002). The stimulus provided by the training allows adaptation and performance improvement to occur. The physical training and conditioning element of basic combat training is also likely to contribute strongly to success. Physical training and the associated improvements in aerobic fitness can improve performance on a number of cognitive tasks (Angevaren, Aufdemkampe, Verhaar, Aleman, \& Vanhees, 2008). Aerobically fit individuals also appear better able to tolerate stress (Silverman \& Deuster, 2014). In scenarios where cognition is crucial, particularly during periods of stress, improving or maintaining physical fitness appears important. For more on the impact of physical fitness on cognition, see the subsection "Aerobic Fitness."

\section{Nutritional Status}

Ten studies examined the impact of aspects of nutritional status on cognitive and military task performance. An overview of these studies is presented in Table 3. Five studies investigated the effect of a nutritional supplement on performance, four studies examined undernutrition, and one study investigated the impact of hydration. Most studies used male participants only, with two studies using both sexes and two studies not specifying. Participants were described as cadets, soldiers, conscripts, pilots, members of a paramilitary force, elite combat unit soldiers, or special forces.

Undernutrition. Undernutrition resulting from the consumption of lightweight rations appeared to impair performance on tasks of processing speed, but only when the period of ration consumption was extended (e.g., 30 days). Simple reaction time was $\sim 3 \%$ slower in special forces who consumed lightweight rations $(1,946 \mathrm{kcal})$ for 30 days compared with those who consumed fully nourished rations $(2,782 \mathrm{kcal}$; Lieberman, Askew, Hoyt, Shukitt-Hale, \& Sharp, 1997; Shukitt-Hale, Askew, \& Lieberman, 1997). The number of omission errors on a choice reaction time task was also more than doubled (Shukitt-Hale et al., 1997). In contrast, performance on two vigilance tasks was unaffected by either 12 days of 1,900 kcal (Crowdy, Consolazio, Forbes, Haisman, \& Worsley, 1982) or $24 \mathrm{hr}$ of 2,000 kcal (van Dokkum, van Boxtel, van Dijk, Boer, \& van der Beek, 1996). Twelve days of an energy-restricted diet (1,900 kcal) did not impair performance on a marksmanship task or a grenade throw (Crowdy et al., 1982). For tasks of processing speed, the level of performance impairment appeared more closely aligned to individual changes in plasma amino acid concentration (Lieberman et al., 1997), than the energy restriction itself, possibly explaining why performance was only impaired when the duration of ration consumption was longer. Performance on tasks of simple $(r=-.44)$ and choice reaction time $(r=-.40)$ was associated with a reduction in tryptophan concentration as a consequence of undernutrition (Lieberman et al., 1997). The simple reaction time task required personnel to respond as quickly as possible to a visual stimulus presented at a consistent location. The choice reaction time task required personnel to indicate the location of the visual stimulus presented at a variable location. Long-term starvation can reduce plasma concentrations of many amino acids, with the severity of the decline related to the degree and duration of undernutrition (Felig, Owen, Wahren, \& Cahill, 1969; Peters \& Harper, 1985). Amino acids such as tyrosine and tryptophan form precursors of neurotransmitters thought to be important for cognitive performance and functioning under stress (Banderet \& Lieberman, 1989; Schmitt, Wingen, Ramaekers, Evers, \& Riedel, 2006). It is therefore important to consider the availability of these nutrients in ration packs, in addition to ensuring adequate energy availability.

Dehydration. Dehydration impaired flight simulation performance, but not working memory. Two weeks of a high- or low-fluid diet had no effect on a simple item recognition task (Lindseth, Lindseth, Petros, Jensen, \& Caspers, 2013). The same diet impaired flight simulator performance, but only in pilots who were classified as dehydrated (reduced body mass of $2 \%$ or more). Like undernutrition, it appears that dehydration may impact cognition via impaired neurotransmission (Lieberman, 2007; Popova 


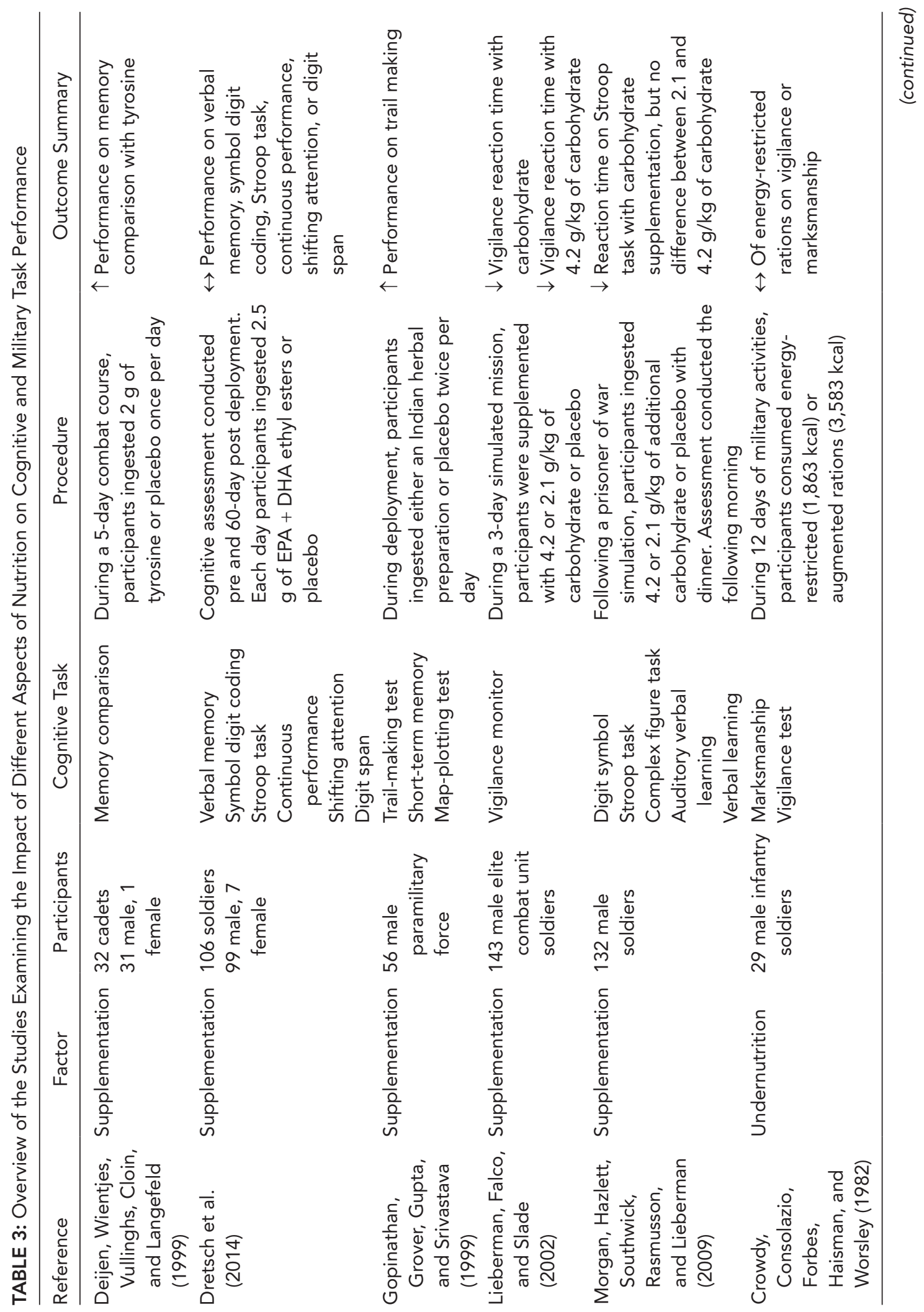




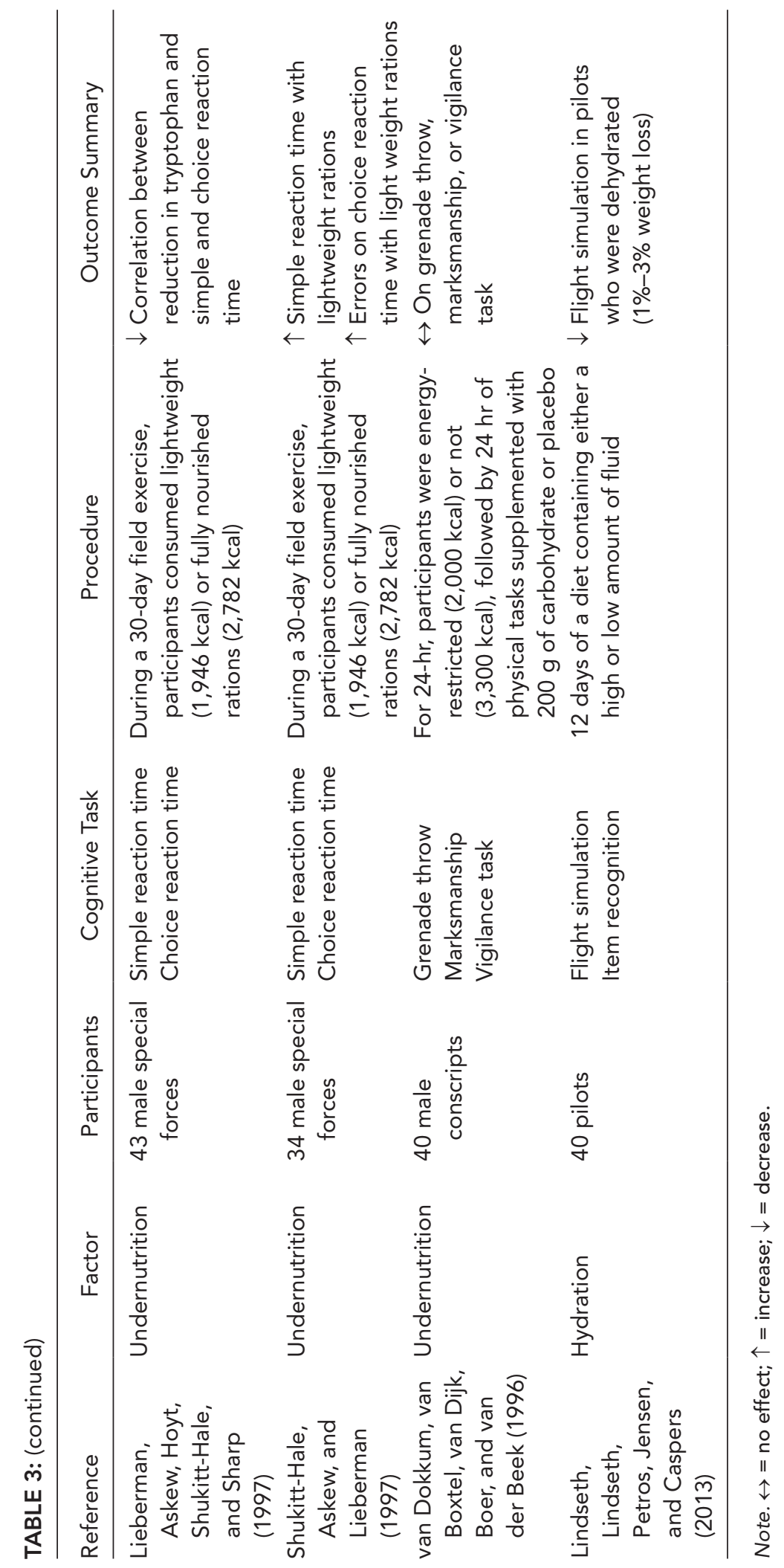


et al., 2001; Wilson \& Morley, 2003) in association with changes in the concentration of electrolytes in the body. Dehydration can also activate the hypothalamic-pituitary-adrenocortical axis and increase the production of stress hormones such as cortisol (Adan, 2012), which may impact performance, as discussed in the "Biological Factors" section. Ensuring adequate hydration is clearly important for health, cognitive, and physical functioning.

Supplementation. Supplementation of various nutrients appears beneficial to the cognitive performance of military personnel by reversing some of the detrimental effects or undernutrition and/or dehydration. Supplementation of carbohydrates during a 72-hr simulated mission improved reaction time on a vigilance task in a dose-response manner. Personnel who ingested carbohydrates responded faster than those who consumed a placebo, with superior performance in those who ingested $4.2 \mathrm{~g} / \mathrm{kg}$ carbohydrate of body mass compared with $2.1 \mathrm{~g} / \mathrm{kg}$ (Lieberman, Falco, \& Slade, 2002). Consuming additional carbohydrates at the completion of a prisoner of war training simulation had no effect on vigilance or working memory the following morning, but improved performance on a response inhibition task (Morgan, Hazlett, Southwick, Rasmusson, \& Lieberman, 2009). Those who ingested the additional carbohydrates exhibited a $65 \%$ greater recovery of performance (completion time) with no difference between those who had 2.1 or $4.2 \mathrm{~g} /$ $\mathrm{kg}$ of body mass. Recent reviews have shown that carbohydrate supplementation is effective at improving aspects of both cognitive (Hoyland, Lawton, \& Dye, 2008) and physical performance (Stellingwerff \& Cox, 2014). In these reviews, carbohydrate is reported as particularly beneficial when cognitive load is high, or exercise performance is prolonged. Furthermore, there is evidence to suggest that simply swirling a carbohydrate solution around the mouth may provide an ergogenic effect (Carter \& McCullough, 2013). This form of administration may be a useful alternative in scenarios where multiple quantities of additional nutrition cannot be carried.

Working memory was better sustained over a 5-day combat course in participants who ingested $2 \mathrm{~g}$ of tyrosine per day (Deijen, Wientjes, Vullinghs, Cloin, \& Langefeld, 1999).
In individuals who consumed a placebo, the number of correct responses was reduced by $\sim 27 \%$ over the 5 days, whereas a reduction of only $9 \%$ was observed in those receiving tyrosine. Tyrosine is an amino acid and precursor of neurotransmitters noradrenaline and dopamine, and under certain conditions is purported to be rate-limiting for brain noradrenaline and dopamine synthesis (Milner \& Wurtman, 1986). Noradrenaline is important for cognitive functions dependent upon the prefrontal cortex including selective attention and working memory (Chamberlain, Müller, Blackwell, Robbins, \& Sahakian, 2006; Cole \& Robbins, 1992; Robbins, 2005). Dopamine is implicated in motivated or goal-directed behaviors, and antagonism (Salamone et al., 1991) and its depletion can cause a reallocation of behavior away from tasks that are effortful (Cannon \& Palmiter, 2003). Similarly to carbohydrate, tyrosine appears particularly effective at maintaining cognitive performance under conditions of stress or high-cognitive load (Jongkees, Hommel, Kühn, \& Colzato, 2015; Neri et al., 1995; O'Brien, Mahoney, Tharion, Sils, \& Castellani, 2007). Periods of intensive training and deployment could be supported by tyrosine supplementation.

An herbal preparation containing plant extracts widely used in Ayurveda, an Indian form of medicine, improved processing speed on a task of attention. Ingesting the preparation twice per day for 8 days increased correct response rate on a trail-making task by $20 \%$ more than placebo, in soldiers on a combat assignment (Gopinathan, Grover, Gupta, \& Srivastava, 1999). In the same participants, no benefit to a working memory or map plotting task was observed. Several Indian herbs, including those used in the above preparation, have been reported to possess anti-stress and endurance promoting effects. In animals, greater tolerance to physical fatigue and hypoxia have been shown with ingestion of similar preparations (Singh, Nath, Mishra, \& Kohli, 1978; Tomar, Singh, Singh, \& Kohli, 1984). These animals also showed reduced gastric ulceration due to stress (Chatterjee, Chakraborty, Pathak, \& Sengupta, 1992; Singh et al., 1978). The potential for similar results to be observed in humans warrants further research. 
The omega-3 fatty acid docosahexaenoic acid is a major structural component of the brain and required for normal membrane structure and signal transduction (W. E. Connor, Neuringer, \& Reisbick, 1992; Horrobin, Jenkins, Bennett, \& Christie, 2002). In animals, low levels of omega-3 are associated with deficits in cognition (Bourre, 2004; Haag, 2003). In humans, higher levels of omega-3 are linked to improvements in a number of mood disorders including major depressive disorder (Antypa, Van der Does, Smelt, \& Rogers, 2009; Kidd, 2007), a disorder of high prevalence in deployed soldiers (Bourre, 2004). Supplementation of $2.5 \mathrm{~g}$ of omega-3 daily had no effect on the attention, working memory, or response inhibition of soldiers during deployment (Dretsch et al., 2014). These data are consistent with the body of research showing inconclusive evidence for benefit to cognition with omega-3 supplementation in humans (Antypa, Smelt, Strengholt, \& Van der Does, 2012; Kotani et al., 2006; Tajalizadekhoob et al., 2011). The authors did note, however, that improvements in cognitive performance may not be observed in such a high-functioning cohort, with benefit more likely in individuals when cognition or mood is clinically impaired (Appleton, Rogers, \& Ness, 2010).

\section{Biological Factors}

Twenty-four studies investigated the effect of a biological factor on cognitive or military task performance. An overview of these studies is presented in Table 4. Eleven studies investigated the effect of a hormone or blood marker on performance, five studies compared aspects of vision, three studies physical fitness, two studies examined pregnancy, one study examined the role of genetics, one study motion sickness symptoms, and one study heart rate variability (HRV). A mixture of male and female participants was utilized, with participants described as military personnel, sailors, pilots, soldiers, marines, air force, cadets, conscripts, draftees, or active duty.

Blood and hormonal markers. Several blood and hormonal markers offer promise in predicting variance in performance on cognitive and military tasks. The most commonly assessed markers are hormones produced in response to stress. Cortisol, for example, appeared to explain substantial variation in attention, working memory, and performance during a mock interrogation, despite differences in the timing of measurement. For tasks of attention and processing speed, the response of cortisol to a cognitive task was associated with choice reaction time $(r=.54)$ and the number of correct responses on a continuous performance task $(r=-.49$; Johnsen, Hansen, Murison, Eid, \& Thayer, 2012). For working memory, evening levels of cortisol were negatively and most strongly correlated with the number of correct responses $(r=$ $-.80)$ and reaction time $(r=-.81)$ on a serial pattern matching test (Johnsen et al., 2012). Cortisol concentration immediately following a mock interrogation was also negatively correlated $(r=$ -.51 ) with performance (Morgan et al., 2004). A similar trend was observed for adrenaline, where the concentration before flight simulation was negatively associated with flight performance (Leino, Leppaluoto, Ruokonen, \& Kuronen, 1999). Both cortisol and adrenaline are hormones secreted by the adrenal glands in response to stress. These hormones appear to preferentially alter processes associated with the prefrontal cortex (Lupien, Gillin, \& Hauger, 1999; Young, Sahakian, Robbins, \& Cowen, 1999) and hippocampus (McEwen, 1999). Acutely, behavior related to these brain regions is altered (Joels \& de Kloet, 1992), and chronic elevation can affect brain morphology (Pruessner et al., 2005).

In contrast to the negative association between cortisol and performance, dehydroepiandrosterone (DHEA) and its metabolite dehydroepiandrosterone sulfate (DHEAS), hormones secreted by the adrenal cortex in response to stress hormone adrenocorticotropin were positively associated with performance on a military task. Furthermore, it appears that DHEAS and the ratio of DHEAS to cortisol may modulate the vulnerability of an individual to stress (Morgan et al., 2004), with DHEAS seemingly able to prevent cortisol-induced performance impairments (Fleshner, Pugh, Tremblay, \& Rudy, 1997; Frye \& Lacey, 1999). A positive correlation was observed between baseline DHEA $(r=.53)$ and DHEAS $(r=.46)$ and accuracy in a nighttime underwater navigation task (Morgan, 


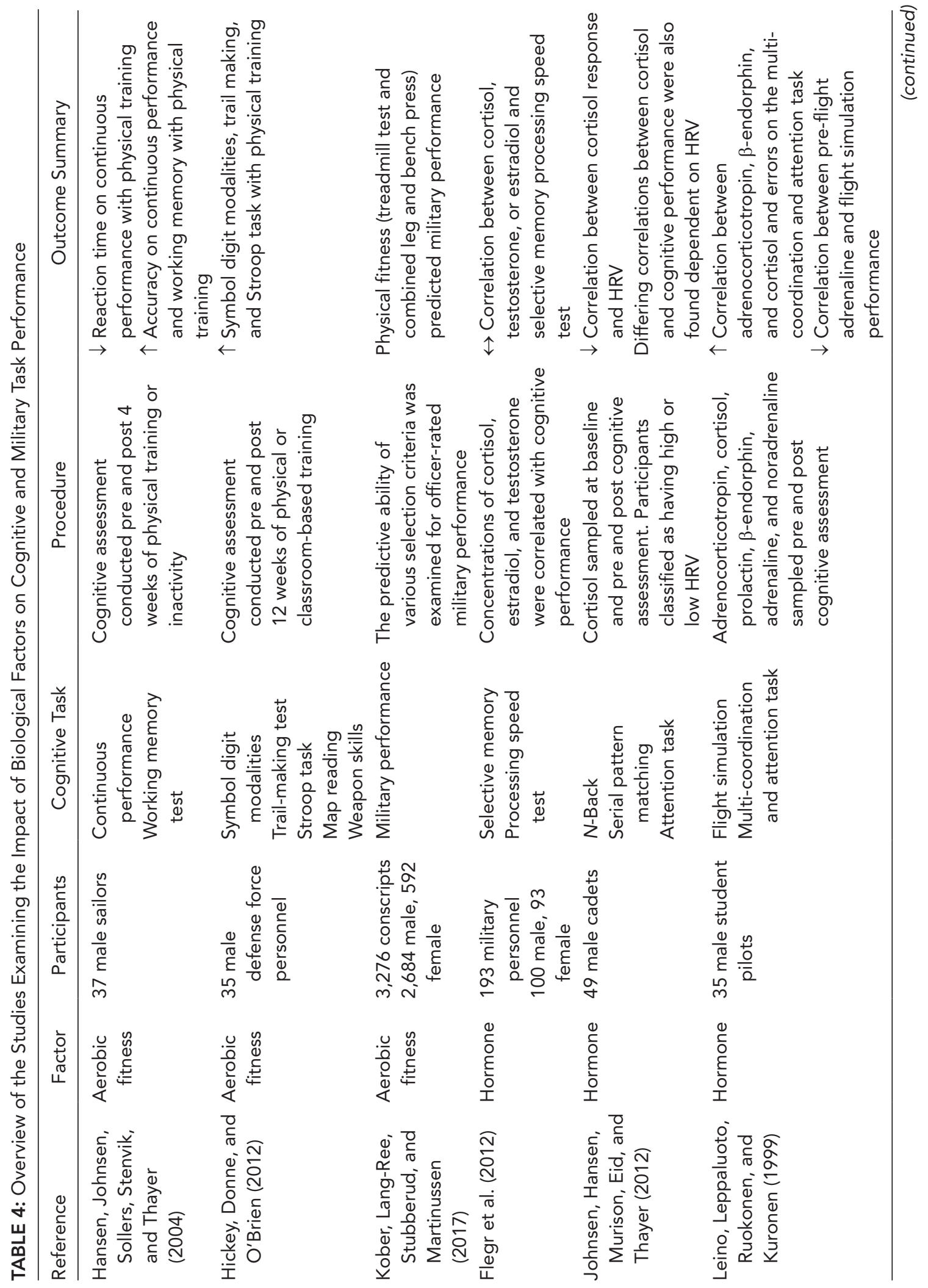




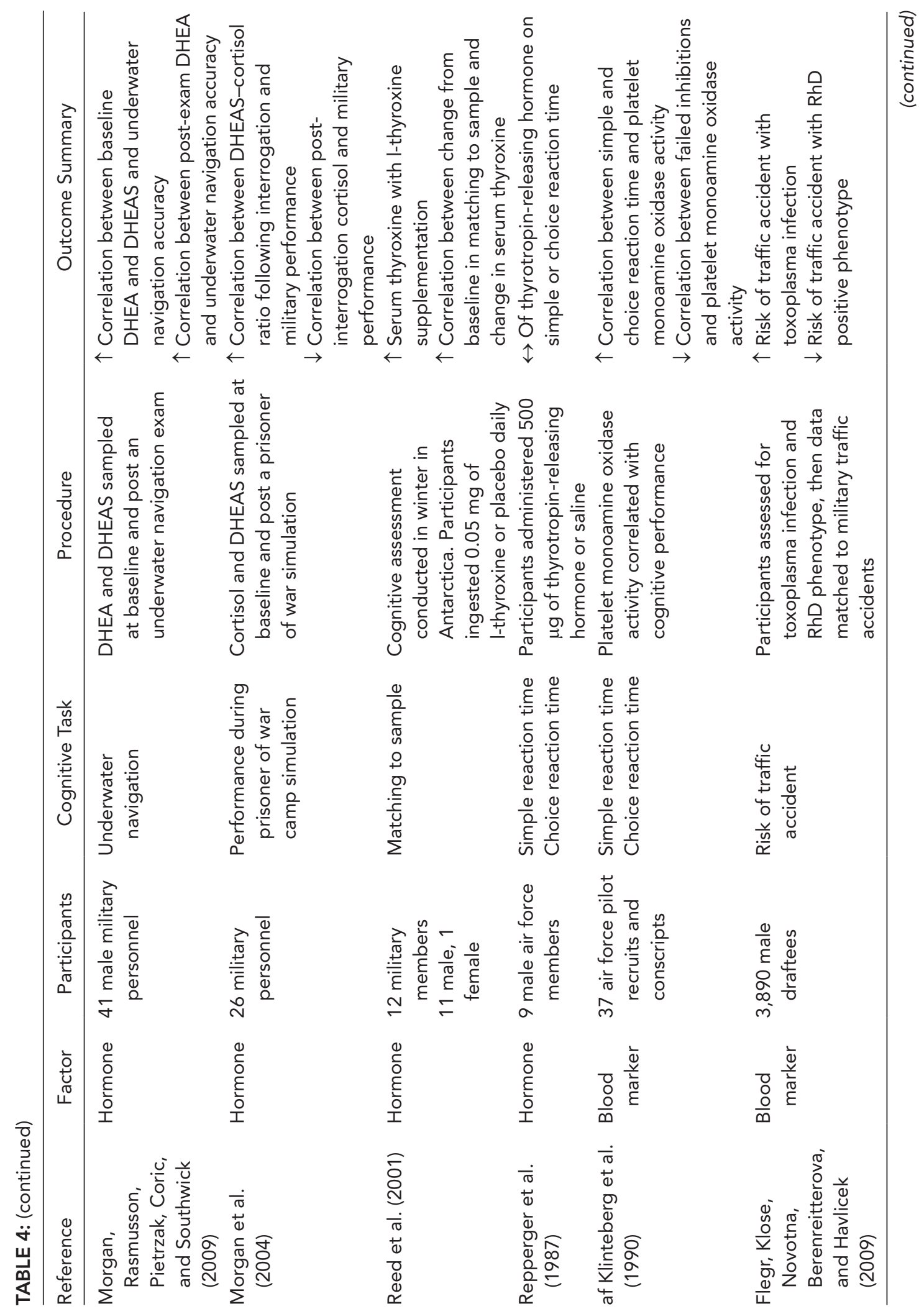




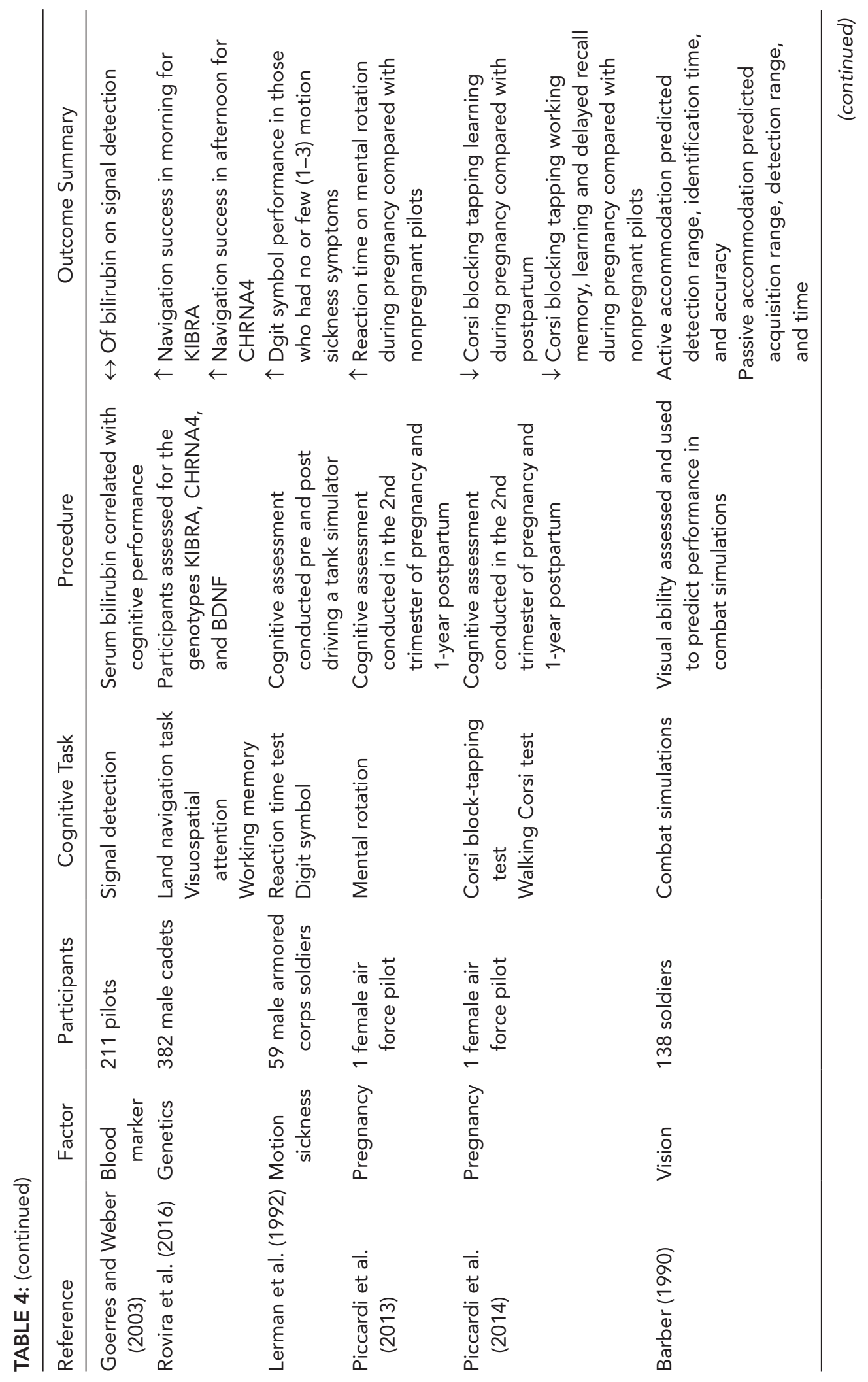




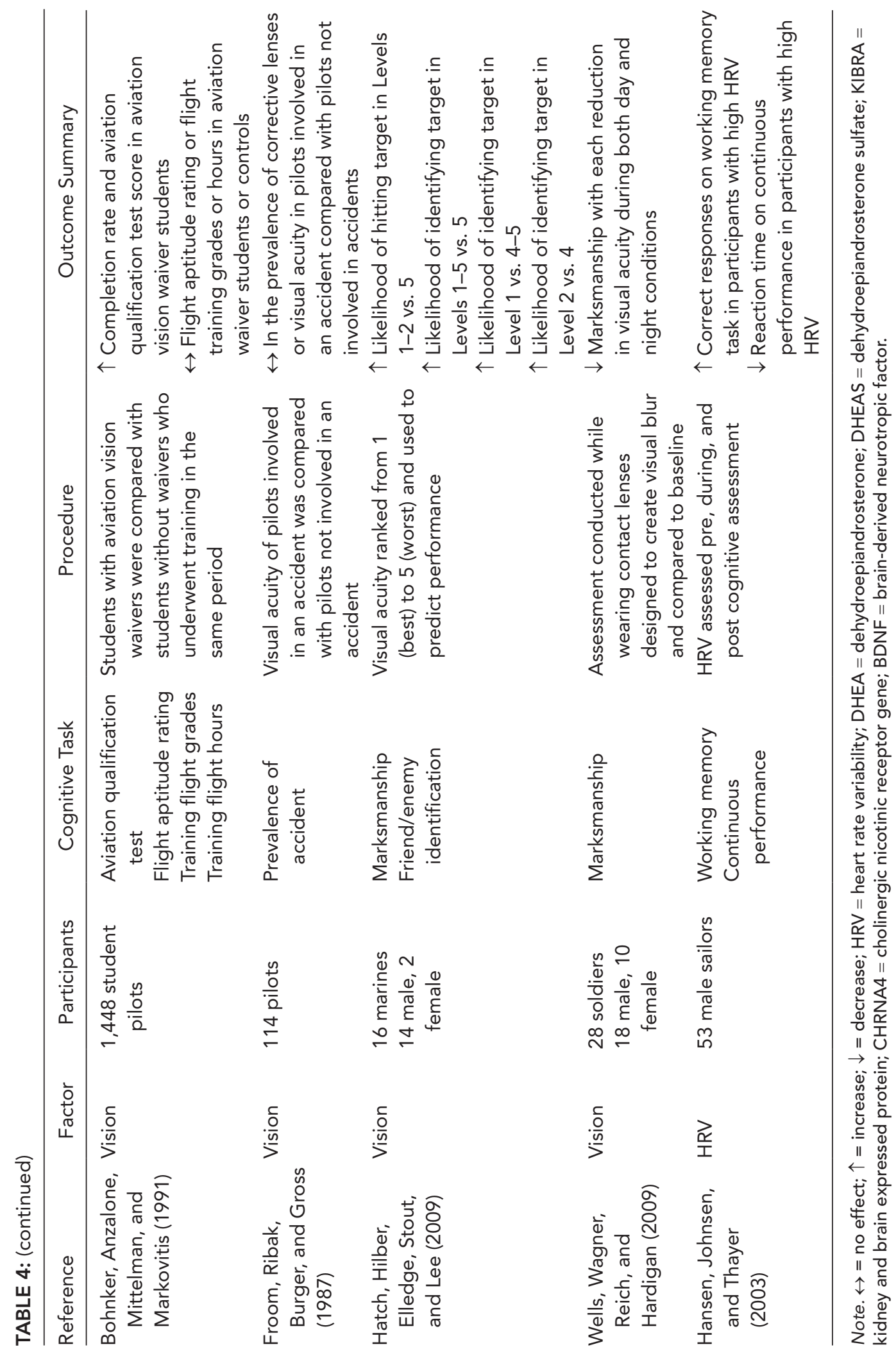


Rasmusson, Pietrzak, Coric, \& Southwick, 2009). A positive correlation was also observed between the ratio of DHEAS to salivary cortisol assessed immediately following an interrogation $(r=.61)$, and instructor-rated performance during a mock prisoner of war camp (Morgan et al., 2004).

Other blood and hormonal markers which could affect cognitive or military task performance include platelet monoamine oxidase activity, thyrotropin-releasing hormone, estradiol, testosterone, thyroxine, and serum bilirubin. Platelet monoamine oxidase activity and thyroxine appear to have positive benefits, while thyrotropin-releasing hormone, sex hormones, and serum bilirubin seem to have no effect. Platelet monoamine oxidase activity was positively, albeit weakly, correlated with auditory and visual simple $(r=.15)$ and choice $(r=.31)$ reaction time (af Klinteberg et al., 1990), and participants with higher thyroxine levels better maintained performance on a working memory task during winter in Antarctica (Reed et al., 2001). No effect of thyrotropin-releasing hormone (Repperger et al., 1987), estradiol (Flegr et al., 2012), testosterone (Flegr et al., 2012), or serum bilirubin was found for tasks of processing speed or attention. Testosterone and estradiol also had no impact on selective memory (Flegr et al., 2012). Toxoplasmosis (an infection caused by the parasite toxoplasma gondii) increased the likelihood of a military person being involved in a traffic accident, while being rhesus-positive with toxoplasma infection was protective (Flegr, Klose, Novotna, Berenreitterova, \& Havlicek, 2009).

Vision. Participants with better vision tended to perform better on military tasks. High visual acuity increased the likelihood of correctly identifying (Hatch, Hilber, Elledge, Stout, \& Lee, 2009) and hitting (Hatch et al., 2009; Wells, Wagner, Reich, \& Hardigan, 2009) a target on a test of marksmanship. Active accommodation, a combination of visual acuity, contrast sensitivity to high spatial frequencies and a near focal point, most strongly predicted fixed wing identification accuracy $(r=-.63)$. Passive accommodation (including resting focus and far focal point; $r=.50$ ) and image interpretation (blur interpretation and contrast sensitivity to low spatial frequencies; $r=.55$ ) were associated with fixed wing acquisition (Barber, 1990). Surprisingly, however, flight performance of personnel with corrected vision was no worse, if not better, than individuals with normal vision. Students with aviation vision waivers had a higher completion rate and aviation qualification test score than control students, with little difference on flight aptitude rating score or flight training hours or grades (Bohnker, Anzalone, Mittelman, \& Markovitis, 1991). Pilots who wore corrective lenses had a similar prevalence of accident when analyzing incidents where visual ability might play a role (i.e., wire and other strikes on low-level flight, disorientation, or errors on landing) than noncorrective lens wearers (Froom, Ribak, Burger, \& Gross, 1987). Selection criteria regarding uncorrected vision may need to be reconsidered.

Aerobic fitness. Aerobic fitness was beneficial to cognition, with training leading to improvement or maintenance of maximal oxygen consumption resulting in better cognitive performance. Greater aerobic fitness was associated with faster reaction time on a continuous performance task, as well as greater accuracy on this task and working memory (Hansen, Johnsen, Sollers, Stenvik, \& Thayer, 2004). An 8-week physical training program which improved maximal oxygen consumption by $5 \%$ improved performance on a task of attention (20\%), working memory (20\%), and response inhibition (24\%; Hickey, Donne, \& O'Brien, 2012). Physical fitness, assessed by an endurance treadmill task and a combined bench and leg press score, was also predictive of officerassessed military performance in both male and female first-year conscripts $(r=.19$; Kober, Lang-Ree, Stubberud, \& Martinussen, 2017). The link between physical activity and aerobic fitness and cognition is well established. Aerobic exercise training improves attention, processing speed, executive function, and memory (Smith et al., 2010), and higher aerobic fitness can moderate functional connections between specific brain regions and networks that support cognitive control (Talukdar et al., 2017). Superior physical fitness may also benefit cognition indirectly by mitigating the impact of other factors detrimental to performance, allowing an 
individual to better accommodate both the stressor and task demand. As an example, greater physical fitness reduces stress reactions to extreme military training (Taylor et al., 2008). Individuals with greater aerobic capacity better tolerate higher core body temperatures in the heat (Selkirk \& McLellan, 2001), report matched physical exertion as less strenuous (Milanez et al., 2011), and are less affected by mental fatigue (Martin et al., 2016). It must be further highlighted that a consistent approach to maintaining aerobic fitness is needed, with impaired reaction time on tasks of executive function apparent after abstaining from structured physical training for only 4 weeks (Hansen et al., 2004). To optimize cognitive performance, regular and consistent physical training, focusing on improving aerobic fitness, should be prioritized in all military personnel.

Pregnancy. Two studies used a female pilot as a case study to assess the effect of pregnancy on cognition. Pregnancy and the postpartum period tended to be associated with poorer working memory compared with nonpregnant female control participants. Pregnancy had no effect on accuracy of a mental rotation task, but reaction time was slower during the second trimester compared with nonpregnant female controls (Piccardi et al., 2013). Compared with controls, working memory, delayed recall, and learning recall were impaired in the pregnant pilot, with working memory remaining worse 1 -year postpartum (Piccardi et al., 2014). In a nonmilitary cohort, the impact of pregnancy on cognition provides mixed results, although these studies typically aim to detect clinical impairment in cognition rather than differences in performance among healthy, highly trained individuals (Buckwalter et al., 1999; Christensen, Poyser, Pollitt, \& Cubis, 1999; Morris, Toms, Easthope, \& Biddulph, 1998). The duration to which cognitive impairment remains also varies with some reports of memory disturbances being resolved as early as 2 days postpartum (Eidelman, Hoffmann, \& Kaitz, 1993), whereas others indicate these deficits persist for 2 months or longer after delivery (de Groot, Vuurman, Hornstra, \& Jolles, 2006). Cognition related to job performance should be assessed in women returning to military activities post pregnancy.
Genetics. While the suitability of genetic testing in an occupational context is surrounded by ethical debate, there is some research linking cognitive performance with certain genes or alleles. In this review, one study examined the impact of genetics on cognition across three different tasks. A variant of the cholinergic nicotinic receptor gene (CHRNA4 rs10044396) thought to influence visuospatial attention was unrelated to performance on a visuospatial attention task (Rovira et al., 2016). Similarly, the genes encoding the kidney and brain expressed protein (KIBRA) and brain-derived neurotropic factor (BDNF) did not predict accuracy on a working memory task (Rovira et al., 2016). These genes were selected based on evidence of association with episodic memory (Milnik et al., 2012) and the ability to focus visuospatial attention (Greenwood, Parasuraman, \& Espeseth, 2012). On a land navigation task, KIBRA was associated with navigation success in the morning, but BDNF was unrelated. In the afternoon, the CHRNA4 genotype was associated with navigation success, while CHRNA4 T allele carriers that had been successful in the morning were the most successful in the afternoon (Rovira et al., 2016). With advances in knowledge and technology, this area may become a burgeoning field of research.

Motion sickness. Motion sickness symptoms arising from driving a tank simulator had no effect on a reaction time task, but impaired performance on a working memory task (Lerman et al., 1992). Participants who reported no (0) or few (1-3) symptoms improved digit symbol performance after driving the simulator compared with baseline, whereas participants who reported four or more symptoms saw no improvement. In civilian studies, motion sickness has been associated with poorer multitasking (Matsangas, McCauley, \& Becker, 2014), working memory (Dahlman, Sjörs, Lindström, Ledin, \& Falkmer, 2009), and visual search performance (Golding \& Kerguelen, 1992). Although outside of the scope of this review, several medications have been designed to treat motion sickness. Aside from their effectiveness in reliving motion sickness, the effects of these drugs on cognitive performance should also be considered (Paul, 
MacLellan, \& Gray, 2005; Weerts, Pattyn, Van de Heyning, \& Wuyts, 2014).

$H R V$. Another stress response that could distinguish between high and low performing individuals is HRV. HRV is the variance in R-R intervals governed by changes in sympathetic and parasympathetic neural activity. Low HRV typically reflects excessive sympathetic and/or inadequate parasympathetic modulation of heart rate (Task Force of the European Society of Cardiology and the North American Society of Pacing and Electrophysiology, 1996), with reduced HRV observed during periods of emotional and physical stress, and increased HRV during periods of rest (Miu, Heilman, \& Miclea, 2009; Nassef et al., 2009). Navy sailors with high baseline HRV responded faster on a continuous performance task than participants with low HRV (Hansen, Johnsen, \& Thayer, 2003). Sailors with high HRV also recorded more correct responses on a task of working memory (Hansen et al., 2003). Combining measurements of HRV and cortisol, individuals with low HRV saw greater cortisol reactivity during cognitive testing but tended to perform better when cortisol concentration was high. Individuals with low HRV exhibited a $123 \%$ greater increase in cortisol in response to cognitive testing than those with high HRV (Johnsen et al., 2012). In addition, in those with low HRV, evening levels of cortisol were positively correlated $(r=.64)$ with performance on a working memory task (Johnsen et al., 2012). In participants with high HRV, this relationship was reversed, morning levels of cortisol were negatively correlated with correct responses $(r=-.61)$, and positively correlated with errors $(r=.51)$ on a serial pattern matching task (Johnsen et al., 2012). While these results form only an initial insight to the use of HRV in a military setting, HRV combined with other measures may be useful in indicating that an individual may respond more positively or negatively to stress. Furthermore, changes in HRV may provide an index of the effectiveness of an intervention at improving cognitive performance under stress. For example, improvements in HRV resulting from interventions such as a 12-week aerobic exercise program (Albinet, Boucard, Bouquet, \& Audiffren, 2010) or biofeedback during task performance (Prinsloo et al., 2011) have produced associated benefits in cognition.

\section{GENERAL DISCUSSION}

In this review, we examined physiological factors that influence cognition in military personnel. Factors including increasing age, fatigue arising from sustained military activities, prolonged undernutrition, dehydration, motion sickness, and pregnancy appear detrimental to cognitive performance. Having high visual acuity, high aerobic fitness, and a high DHEAS to cortisol ratio tended to benefit cognitive performance, as did supplementation with carbohydrates and tyrosine during periods of stress. Personnel with low baseline HRV, an exaggerated cortisol response to stress, or a higher number of stress-related biomarkers at baseline are likely more susceptible to performance decline. Among the factors recognized as influencing cognition, a further subset was considered modifiable. Modifiable factors are variables that can be manipulated to minimize the harm, or maximize the benefit to performance, and include nutrition, hydration, and aerobic fitness. By identifying the factors that influence cognition, strategies or interventions can be developed, evaluated, and then implemented to provide personnel the best opportunity to perform effectively during military training and deployment.

Greater aerobic fitness was associated with better cognitive and military task performance. Military training, which can improve aerobic fitness (Dyrstad, Soltvedt, \& Hallén, 2006; Legg \& Duggan, 1996), also improved aspects of cognition. The benefit of physical training and improved cardiorespiratory fitness to cognition are well established; however, greater aerobic fitness may also improve cognition indirectly by mitigating the impact of other stressors such as physical and mental demand and heat stress, allowing an individual to better accommodate both these and the task demands. It is also important to note that a consistent approach to maintaining aerobic fitness is needed, with impairments in cognitive performance observed after only 4 weeks of abstaining from structured physical training (Hansen et al., 2004). To optimize cognitive performance, regular and 
consistent physical training focusing on improving aerobic fitness should be a priority for all military personnel, even those with nonphysical roles. Physical training may also be considered in non-deployed personnel as a method to improve the capacity of dealing with stress.

Physiological biomarkers of stress including HRV and several stress-related hormones may be useful in understanding variations in performance. Individuals with an exaggerated stress response, as well as greater prevalence of stressrelated biomarkers at baseline, tended to perform worse on cognitive tasks or suffer greater decline in performance over time. An exacerbated physiological response to a stressor is generally viewed as maladaptive or reflecting a heightened sensitivity to the context of the stress (Calabrese et al., 2007). Personnel who are identified as experiencing such responses might benefit from the practice of stress-reducing techniques. In military personnel, interventions including yoga and mindfulness have been associated with decreased waking cortisol (Rocha et al., 2012), and a reduced cortisol and HRV response following a submarine escape training exercise (Trousselard, 2009). Mindfulness training has been shown to improve cognition through a reduction in lapses on a sustained attention to response task (Jha et al., 2015) and better working memory over the stressful predeployment period (Jha et al., 2010). Other factors including aerobic fitness can reduce biochemical and self-reported measures of stress and anxiety during and following exposure to a series of psychosocial stressors (Sinyor, Schwartz, Peronnet, Brisson, \& Seraganian, 1983). Identifying individuals vulnerable to performance decrements with physiological and psychological stress could be achieved via testing of biomarkers during stressful simulation training. These individuals should then be targeted with the appropriate interventions, with strategies implemented during both intense periods of preparatory training and deployment.

Undernutrition resulting from the prolonged consumption of lightweight rations, as well as dehydration from ingestion of a lowfluid diet, impaired aspects of cognition. For both conditions, the changes in cognitive performance are likely associated with impaired neurotransmission. For undernutrition, the changes in cognition are more closely aligned to individual changes in plasma amino acid concentration than the energy restriction itself (Lieberman et al., 1997). Amino acids such as tryptophan and tyrosine are important in the synthesis of neurotransmitters thought to be implicated in cognition (Milner \& Wurtman, 1986), and supplementation of these amino acids can improve cognition (Mohajeri et al., 2015; Murphy, Longhitano, Ayres, Cowen, \& Harmer, 2006), particularly during periods of stress (Deijen et al., 1999; O’Brien et al., 2007). For dehydration, impairment in neurotransmission is largely related to changes in the concentration of electrolytes in the body (Popova et al., 2001). Dehydration can activate the hypothalamic-pituitary-adrenocortical axis (Adan, 2012), magnifying any cognitive impairments associated with stress. When considering strategies to safeguard against undernutrition or dehydration-induced cognitive deficits, these subtleties should be considered. During periods where nutrition may be insufficient, priority should be given to a diet high in protein and carbohydrate, containing sufficient levels of amino acids that synthesize neurotransmitters involved in cognition. Where a sufficient diet cannot be provided, pre-deployment supplementation may be worthwhile. Where dehydration is concerned, rehydration using energy drinks, for example, may be advantageous with a combination of fluid and electrolytes. These beverages can be effective in restoring both cognitive and physical performance following dehydration (Bailey et al., 2008; Kalman, Feldman, Krieger, \& Bloomer, 2012), and enhancing performance when physically and/or mentally fatigued (Lieberman et al., 2002).

\section{CONCLUSION}

Several physiological factors have a positive or negative impact on cognition. Some of these factors are modifiable and should be targeted for interventions in military settings to improve cognitive performance. Increasing or maintaining aerobic fitness impacts cognition directly and improves the ability to accommodate other stressors. Maintaining an adequate diet and hydration status ensures effective brain functioning in regard to neurotransmission. 
Targeting individuals who recorded a greater physiological response to stress for interventions designed to reduce stress and anxiety may also reduce performance impairment with stress. By identifying and considering physiological factors which influence cognition, coupled with other physical, psychological, and environmental factors, military personnel can be more comprehensively prepared to face potential stressors. This information will inform the evaluation and development of strategies and programs designed to enhance cognitive performance specific to military training and deployment contexts.

\section{ACKNOWLEDGMENTS}

This project was funded by a Defence Science and Technology Human Performance Research Network grant (grant number 201941). The funding source was not involved in the study design, data collection, writing process, or the decision to submit the article for publication.

\section{KEY POINTS}

- Several physiological states and traits can influence cognition, and as such, where cognitive performance is important, these factors should be considered.

- Factors identified as having a positive impact on cognition included aerobic fitness, nutritional supplementation, and visual acuity.

- Factors identified as having a negative impact included fatigue arising from sustained military activities, dehydration, undernutrition, and an exaggerated physiological stress response to a cognitive task or stressor.

- Modifiable factors should be targeted for manipulation during the training and preparation of personnel for deployment, alongside typical preparation methods.

\section{ORCID IDS}

Kristy Martin (iD) https://orcid.org/0000-00030953-7595

Ben Rattray (iD) https://orcid.org/0000-00021652-7726

David B. Pyne (iD https://orcid.org/0000-00031555-5079

\section{SUPPLEMENTAL MATERIAL}

The online supplemental material is available with the manuscript on the $H F$ website.

\section{REFERENCES}

Adan, A. (2012). Cognitive performance and dehydration. Journal of the American College of Nutrition, 31, 71-78.

af Klinteberg, B., Oreland, L., Hallman, J., Wirsén, A., Levander, S. E., \& Schalling, D. (1990). Exploring the connections between platelet monoamine oxidase activity and behavior: Relationships with performance in neuropsychological tasks. Neuropsychobiology, 23, 188-196. doi:10.1159/000119451

Albinet, C. T., Boucard, G., Bouquet, C. A., \& Audiffren, M. (2010). Increased heart rate variability and executive performance after aerobic training in the elderly. European Journal of Applied Physiology, 109, 617-624.

Alfred, P. E., \& Rice, V. J. (2012, September). Age differences in simple and procedural reaction time among healthy military personnel. Paper presented at the Proceedings of the Human Factors and Ergonomics Society, Los Angeles, CA.

Angevaren, M., Aufdemkampe, G., Verhaar, H. J., Aleman, A., \& Vanhees, L. (2008). Physical activity and enhanced fitness to improve cognitive function in older people without known cognitive impairment. Cochrane Database of Systematic Reviews, 3(3), 1-73.

Antypa, N., Smelt, A. H., Strengholt, A., \& Van der Does, A. W. (2012). Effects of omega-3 fatty acid supplementation on mood and emotional information processing in recovered depressed individuals. Journal of Psychopharmacology, 26, 738-743.

Antypa, N., Van der Does, A. J. W., Smelt, A. H. M., \& Rogers, R. D. (2009). Omega-3 fatty acids (fish-oil) and depressionrelated cognition in healthy volunteers. Journal of Psychopharmacology, 23, 831-840.

Appleton, K. M., Rogers, P. J., \& Ness, A. R. (2010). Updated systematic review and meta-analysis of the effects of $n-3$ longchain polyunsaturated fatty acids on depressed mood. The American Journal of Clinical Nutrition, 91, 757-770.

Ardoy, D. N., Fernández-Rodríguez, J. M., Jiménez-Pavón, D., Castillo, R., Ruiz, J. R., \& Ortega, F. B. (2014). A physical education trial improves adolescents' cognitive performance and academic achievement: The EDUFIT study. Scandinavian Journal of Medicine \& Science in Sports, 24(1), e52-e61.

Avolio, B. J., \& Waldman, D. A. (1994). Variations in cognitive, perceptual, and psychomotor abilities across the working life span: Examining the effects of race, sex, experience, education, and occupational type. Psychology and Aging, 9, 430-442.

Bailey, S. P., Holt, C., Pfluger, K. C., Budde, Z. L., Afergan, D., Stripling, R., . . Hall, E. E. (2008). Impact of prolonged exercise in the heat and carbohydrate supplementation on performance of a virtual environment task. Military Medicine, 173, 187-192. doi:10.7205/MILMED.173.2.187

Ball, K., Berch, D. B., Helmers, K. F., Jobe, J. B., Leveck, M. D., Marsiske, M., . . . Willis, S. L. (2002). Effects of cognitive training interventions with older adults: A randomized controlled trial. Journal of the American Medical Association, 288, 2271-2281.

Banderet, L. E., \& Lieberman, H. R. (1989). Treatment with tyrosine, a neurotransmitter precursor, reduces environmental stress in humans. Brain Research Bulletin, 22, 759-762.

Barber, A. V. (1990). Visual mechanisms and predictors of far field visual task performance. Human Factors, 32, 217-233. doi:10.1177/001872089003200208 
Bermejo, J. L., Garcia-Masso, X., Paillard, T., \& Noe, F. (2018). Fatigue does not conjointly alter postural and cognitive performance when standing in a shooting position under dual-task conditions. Journal Sports Sciences, 36, 429-435. doi:10.1080 /02640414.2017.1313443

Bhattacharyya, D., Pal, M., Chatterjee, T., \& Majumdar, D. (2017). Effect of load carriage and natural terrain conditions on cognitive performance in desert environments. Physiology \& Behaviour, 179, 253-261. doi:10.1016/j.physbeh.2017.06.014

Bohnker, B., Anzalone, F., Mittelman, M., \& Markovitis, A. (1991). Primary flight training performance of student naval aviators with vision waivers. Aviation, Space, and Environmental Medicine, 62, 162-164.

Bonnet, M. H. (1980). Sleep, performance and mood after the energy-expenditure equivalent of 40 hours of sleep-deprivation. Psychophysiology, 17, 56-63. doi:10.1111/j.1469-8986.1980. tb02460.x

Bourre, J. M. (2004). Roles of unsaturated fatty acids (especially omega-3 fatty acids) in the brain at various ages and during ageing. The Journal of Nutrition, Health \& Aging, 8, 163-174.

Buckman, J. E., Sundin, J., Greene, T., Fear, N. T., Dandeker, C., Greenberg, N., \& Wessely, S. (2011). The impact of deployment length on the health and well-being of military personnel: A systematic review of the literature. Occupational \& Environmental Medicine, 68, 69-76.

Buckwalter, J. G., Stanczyk, F. Z., McCleary, C. A., Bluestein, B. W., Buckwalter, D. K., Rankin, K. P., . . Goodwin, T. M. (1999). Pregnancy, the postpartum, and steroid hormones: Effects on cognition and mood. Psychoneuroendocrinology, 24, 69-84.

Buguet, A., Montmayeur, A., Pigeau, R., \& Naitoh, P. (1995). Modafinil, d-amphetamine and placebo during 64 hours of sustained mental work. II. Effects on two nights of recovery sleep. Journal of Sleep Research, 4, 229-241.

Calabrese, E. J., Bachmann, K. A., Bailer, A. J., Bolger, P. M., Borak, J., Cai, L., . . . Cook, R. R. (2007). Biological stress response terminology: Integrating the concepts of adaptive response and preconditioning stress within a hormetic doseresponse framework. Toxicology and Applied Pharmacology, 222, 122-128.

Caldwell, J. A., Jr., \& LeDuc, P. A. (1998). Gender influences on performance, mood and recovery sleep in fatigued aviators. Ergonomics, 41, 1757-1770. doi:10.1080/001401398185956

Campbell, D. J., \& Nobel, O. B. Y. (2009). Occupational stressors in military service: A review and framework. Military Psychology, 21(Suppl. 2), S1-S21.

Cannon, C. M., \& Palmiter, R. D. (2003). Reward without dopamine. The Journal of Neuroscience, 23, 10827-10831.

Carter, E. C., \& McCullough, M. E. (2013). After a pair of selfcontrol-intensive tasks, sucrose swishing improves subsequent working memory performance. BMC Psychology, 1, Article 22. doi:10.1186/2050-7283-1-22

Chamberlain, S. R., Müller, U., Blackwell, A. D., Robbins, T. W., \& Sahakian, B. J. (2006). Noradrenergic modulation of working memory and emotional memory in humans. Psychopharmacology, 188, 397-407.

Chance, J. E., \& Goldstein, A. G. (1971). Internal-external control of reinforcement embedded-figures performance. Perception \& Psychophysics, 9, 33-34.

Chang, Y. K., Labban, J. D., Gapin, J. I., \& Etnier, J. L. (2012). The effects of acute exercise on cognitive performance: A metaanalysis. Brain Research, 1453, 87-101.

Chatterjee, T. K., Chakraborty, A., Pathak, M., \& Sengupta, G. C. (1992). Effects of plant extract Centella asiatica (Linn.) on cold restraint stress ulcer in rats. Indian Journal of Experimental Biology, 30, 889-891.

Christensen, H., Poyser, C., Pollitt, P., \& Cubis, J. (1999). Pregnancy may confer a selective cognitive advantage. Journal of Reproductive and Infant Psychology, 17, 7-25.

Colcombe, S. J., Erickson, K. I., Raz, N., Webb, A. G., Cohen, N. J., McAuley, E., \& Kramer, A. F. (2003). Aerobic fitness reduces brain tissue loss in aging humans. The Journals of Gerontology, Series A: Biological Sciences \& Medical Sciences, 58, 176-180.

Colcombe, S. J., \& Kramer, A. F. (2003). Fitness effects on the cognitive function of older adults: A meta-analytic study. Psychological Science, 14, 125-130.

Cole, B. J., \& Robbins, T. W. (1992). Forebrain norepinephrine: Role in controlled information processing in the rat. Neuropsychopharmacology, 7, 129-142.

Connor, J. M., Serbin, L. A., \& Schakman, M. (1977). Sex differences in children responses to training in a visual-spatial test. Developmental Psychology, 13, 293-294.

Connor, W. E., Neuringer, M., \& Reisbick, S. (1992). Essential fatty acids: The importance of $n-3$ fatty acids in the retina and brain. Nutrition Reviews, 50(4), 21-29.

Crowdy, J. P., Consolazio, C. F., Forbes, A. L., Haisman, M. F., \& Worsley, D. E. (1982). Nutrition in adverse environments, 3. The metabolic effects of a restricted food intake on men working in a tropical environment. Human Nutrition. Applied Nutrition, 36, 325-344.

Dahlman, J., Sjörs, A., Lindström, J., Ledin, T., \& Falkmer, T. (2009). Performance and autonomic responses during motion sickness. Human Factors, 51, 56-66.

Deary, I. J., Corley, J., Gow, A. J., Harris, S. E., Houlihan, L. M., Marioni, R. E., . . Starr, J. M. (2009). Age-associated cognitive decline. British Medical Bulletin, 92, 135-152.

de Groot, R. H., Vuurman, E. F., Hornstra, G., \& Jolles, J. (2006). Differences in cognitive performance during pregnancy and early motherhood. Psychological Medicine, 36, 1023-1032.

Deijen, J. B., Wientjes, C. J., Vullinghs, H. F., Cloin, P. A., \& Langefeld, J. J. (1999). Tyrosine improves cognitive performance and reduces blood pressure in cadets after one week of a combat training course. Brain Research Bulletin, 48, 203-209.

Dretsch, M. N., Johnston, D., Bradley, R. S., MacRae, H., Deuster, P. A., \& Harris, W. S. (2014). Effects of omega-3 fatty acid supplementation on neurocognitive functioning and mood in deployed U.S. soldiers: A pilot study. Military Medicine, 179, 396-403. doi:10.7205/milmed-d-13-00395

Dyrstad, S. M., Soltvedt, R., \& Hallén, J. (2006). Physical fitness and physical training during Norwegian military service. Military Medicine, 171, 736-741.

Eddy, M. D., Hasselquist, L., Giles, G., Hayes, J. F., Howe, J., Rourke, J., . . . Mahoney, C. R. (2015). The effects of load carriage and physical fatigue on cognitive performance. PLoS ONE, 10(7), e 0130817. doi:10.1371/journal.pone.0130817

Eidelman, A. I., Hoffmann, N. W., \& Kaitz, M. (1993). Cognitive deficits in women after childbirth. Obstetrics \& Gynecology, 81, 764-767.

Felig, P., Owen, O. E., Wahren, J., \& Cahill, J. H. J. (1969). Amino acid metabolism during prolonged starvation. Journal of Clinical Investigation, 48, 584-594.

Flegr, J., Hampl, R., Cernochova, D., Preiss, M., Bicikova, M., Sieger, L., . . Klose, J. (2012). The relation of cortisol and sex hormone levels to results of psychological, performance, IQ and memory tests in military men and women. Neuroendocrinology Letters, 33, 224-235. 
Flegr, J., Klose, J., Novotna, M., Berenreitterova, M., \& Havlicek, J. (2009). Increased incidence of traffic accidents in toxoplasma-infected military drivers and protective effect $\mathrm{RhD}$ molecule revealed by a large-scale prospective cohort study. BMC Infectious Diseases, 9, Article 72. doi:10.1186/14712334-9-72

Fleshner, M., Pugh, C. R., Tremblay, D., \& Rudy, J. W. (1997). DHEA-S selectively impairs contextual-fear conditioning: Support for the antiglucocorticoid hypothesis. Behavioral Neuroscience, 111, 512-517.

Froom, P., Ribak, J., Burger, A., \& Gross, M. (1987). Visual acuity, corrective lenses, and accidents in helicopter pilots. Aviation, Space, and Environmental Medicine, 58, 252-253.

Frye, C. A., \& Lacey, E. H. (1999). The neurosteroids DHEA and DHEAS may influence cognitive performance by altering affective state. Physiology \& Behavior, 66, 85-92.

Goerres, H. P., \& Weber, F. (2003). Elevated bilirubin and visual perception in pilots. Aviation, Space, and Environmental Medicine, 74(3), 278-280.

Golding, J. F., \& Kerguelen, M. (1992). A comparison of the nauseogenic potential of low-frequency vertical versus horizontal linear oscillation. Aviation, Space, and Environmental Medicine, 63, 491-497.

Goldstein, A. G., \& Chance, J. E. (1965). Effects of practice on sex-related different performance on embedded figures. Psychonomic Science, 3, 361-362.

Gopinathan, P. M., Grover, S. K., Gupta, A. K., \& Srivastava, K. K. (1999). Effects of a composite Indian herbal preparation on combat effectiveness in low-intensity-conflict operations. Military Medicine, 164, 814-819.

Greenwood, P. M., Parasuraman, R., \& Espeseth, T. (2012). A cognitive phenotype for a polymorphism in the nicotinic receptor gene CHRNA4. Neuroscience \& Biobehavioral Reviews, 36, 1331-1341.

Guo, W., Chen, G., Qin, J., Zhang, J., Guo, X., Yu, J., . . Huang, L. (2016). Short-term high-altitude pre-exposure improves neurobehavioral ability. NeuroReport, 27, 367-373. doi:10.1097/ wnr.0000000000000537

Haag, M. (2003). Essential fatty acids and the brain. The Canadian Journal of Psychiatry, 48, 195-203.

Hansen, A. L., Johnsen, B. H., Sollers, J. J., III., Stenvik, K., \& Thayer, J. F. (2004). Heart rate variability and its relation to prefrontal cognitive function: The effects of training and detraining. European Journal of Applied Physiology, 93, 263272. doi:10.1007/s00421-004-1208-0

Hansen, A. L., Johnsen, B. H., \& Thayer, J. E. (2003). Vagal influence on working memory and attention. International Journal of Psychophysiology, 48, 263-274. doi:10.1016/ s0167-8760(03)00073-4

Harrison, Y., \& Horne, J. A. (2000). The impact of sleep deprivation on decision making: A review. Journal of Experimental Psychology: Applied, 6, 236-249.

Hatch, B. C., Hilber, D. J., Elledge, J. B., Stout, J. W., \& Lee, R. B. (2009). The effects of visual acuity on target discrimination and shooting performance. Optometry and Vision Science, 86, 1359-1367. doi:10.1097/OPX.0b013e3181be9740

Head, J., Tenan, M. S., Tweedell, A. J., LaFiandra, M. E., Morelli, F., Wilson, K. M., . . . Helton, W. S. (2017). Prior mental fatigue impairs marksmanship decision performance. Frontiers in Physiology, 8, Article 680. doi:10.3389/fphys.2017.00680

Heaton, R. K., Ryan, L., Grant, I., \& Matthews, C. G. (1996). Demographic influences on neuropsychological test performance. In I. Grant \& K. Adams (Eds.), Neuropsychological assessment of neuropsychiatric disorders (2nd ed., pp. 141163). New York, NY: Oxford University Press.

Hellewell, S. C., \& Cernak, I. (2018). Measuring resilience to operational stress in Canadian armed forces personnel. Journal of Traumatic Stress, 31, 89-101. doi:10.1002/jts.22261

Hickey, J. P., Donne, B., \& O’Brien, D. (2012). Effects of an eight week military training program on aerobic indices and psychomotor function. Journal of the Royal Army Medical Corps, 158(1), 41-46.

Horrobin, D. F., Jenkins, K., Bennett, C. N., \& Christie, W. W. (2002). Eicosapentaenoic acid and arachidonic acid: Collaboration and not antagonism is the key to biological understanding. Prostaglandins, Leukotrienes \& Essential Fatty Acids, 66, 83-90.

Hoyland, A., Lawton, C. L., \& Dye, L. (2008). Acute effects of macronutrient manipulations on cognitive test performance in healthy young adults: A systematic research review. Neuroscience \& Biobehavioral Reviews, 32, 72-85.

James, J. E. (1998). Acute and chronic effects of caffeine on performance, mood, headache, and sleep. Neuropsychobiology, $38(1), 32-41$.

Jha, A. P., Morrison, A. B., Dainer-Best, J., Parker, S., Rostrup, N., \& Stanley, E. A. (2015). Minds "at attention": Mindfulness training curbs attentional lapses in military cohorts. PLoS ONE, 10(2), e0116889. doi:10.1371/journal.pone.0116889

Jha, A. P., Stanley, E. A., Kiyonaga, A., Wong, L., \& Gelfand, L. (2010). Examining the protective effects of mindfulness training on working memory capacity and affective experience. Emotion, 10, 54-64. doi:10.1037/a0018438

Joels, M., \& de Kloet, E. R. (1992). Control of neuronal excitability by corticosteroid hormones. Trends in Neuroscience, 15(1), 25-30.

Johnsen, B. H., Hansen, A. L., Murison, R., Eid, J., \& Thayer, J. F. (2012). Heart rate variability and cortisol responses during attentional and working memory tasks in naval cadets. International Maritime Health, 63, 181-187.

Jongkees, B. J., Hommel, B., Kühn, S., \& Colzato, L. S. (2015). Effect of tyrosine supplementation on clinical and healthy populations under stress or cognitive demands-A review. Journal of Psychiatric Research, 70, 50-57.

Kalman, D. S., Feldman, S., Krieger, D. R., \& Bloomer, R. J. (2012). Comparison of coconut water and a carbohydrateelectrolyte sport drink on measures of hydration and physical performance in exercise-trained men. Journal of the International Society of Sports Nutrition, 9, Article 1. doi:10.1186/1550-2783-9-1

Kemnitz, C. P., Johnson, R. F., Merullo, D. J., \& Rice, V. J. (2001). Relation of rifle stock length and weight to military rifle marksmanship performance by men and women. Perceptual Motor Skills, 93, 479-485. doi:10.2466/pms.2001.93.2.479

Kidd, P. M. (2007). Omega-3 DHA and EPA for cognition, behavior, and mood: Clinical findings and structural-functional synergies with cell membrane phospholipids. Alternative Medicine Review, 12, 207-227.

Knapik, J. J., Ang, P., Meiselman, H., Johnson, W., Kirk, J., Bensel, C., \& Hanlon, W. (1997). Soldier performance and strenuous road marching: Influence of load mass and load distribution. Military Medicine, 162, 62-67.

Knapik, J. J., Rieger, W., Palkoska, F., Van Camp, S., \& Darakjy, S. (2009). United States Army physical readiness training: Rationale and evaluation of the physical training doctrine. Journal of Strength and Conditioning Research, 23, 1353-1362.

Kober, P. K., Lang-Ree, O. C., Stubberud, K. V., \& Martinussen, M. (2017). Predicting basic military performance for 
conscripts in the Norwegian armed forces. Military Psychology, 29, 560-569. doi:10.1037/mil0000192

Kotani, S., Sakaguchi, E., Warashina, S., Matsukawa, N., Ishikura, Y., Kiso, Y., . . Y Yamashima, T. (2006). Dietary supplementation of arachidonic and docosahexaenoic acids improves cognitive dysfunction. Neuroscience Research, 56, 159-164.

Leckliter, I. N., \& Matarazzo, J. D. (1989). The influence of age, education, IQ, gender, and alcohol abuse on Halstead-Reitan Neuropsychological Test Battery performance. Journal of Clinical Psychology, 45, 484-512.

Legg, S. J., \& Duggan, A. (1996). The effects of basic training on aerobic fitness and muscular strength and endurance of British Army recruits. Ergonomics, 39, 1403-1418.

Leino, T. K., Leppaluoto, J., Ruokonen, A., \& Kuronen, P. (1999). Neuroendocrine responses to psychological workload of instrument flying in student pilots. Aviation, Space, and Environmental Medicine, 70, 565-570.

Lerman, Y., Sadovsky, G., Goldberg, E., Kedem, R., Peritz, E., \& Pines, A. (1992). Motion sickness-like syndrome among tank simulator drivers. Israel Medical Association Journal, 28, 610-615.

Lezak, M. D., Howieson, D. B., \& Loring, D. W. (2004). Neuropsychological assessment (4th ed.). New York, NY: Oxford University Press.

Lieberman, H. R. (2003). Nutrition, brain function and cognitive performance. Appetite, 40, 245-254.

Lieberman, H. R. (2007). Hydration and cognition: A critical review and recommendations for future research. The Journal of the American College of Nutrition, 26(Suppl. 5), 555-561.

Lieberman, H. R., Askew, E. W., Hoyt, R. W., Shukitt-Hale, B., \& Sharp, M. A. (1997). Effects of 30 days of undernutrition on plasma neurotransmitter precursors, other amino acids, and behavior. The Journal of Nutritional Biochemistry, 8, 119-126. doi:10.1016/s0955-2863(97)00008-9

Lieberman, H. R., Falco, C. M., \& Slade, S. S. (2002). Carbohydrate administration during a day of sustained aerobic activity improves vigilance, as assessed by a novel ambulatory monitoring device, and mood. The Journal of the American College of Nutrition, 76, 120-127.

Lieberman, H. R., Karl, J. P., Niro, P. J., Williams, K. W., Farina, E. K., Cable, S. J., \& McClung, J. P. (2014). Positive effects of basic training on cognitive performance and mood of adult females. Human Factors, 56, 1113-1123. doi: $10.1177 / 0018720813519472$

Lim, J., \& Dinges, D. F. (2010). A meta-analysis of the impact of short-term sleep deprivation on cognitive variables. Psychological Bulletin, 136, 375-389.

Lindseth, P. D., Lindseth, G. N., Petros, T. V., Jensen, W. C., \& Caspers, J. (2013). Effects of hydration on cognitive function of pilots. Military Medicine, 178, 792-798. doi:10.7205/ milmed-d-13-00013

Lorist, M. M., Boksem, M. A., \& Ridderinkhof, K. R. (2005). Impaired cognitive control and reduced cingulate activity during mental fatigue. Cognitive Brain Research, 24, 199-205.

Lupien, S. J., Gillin, C. J., \& Hauger, R. L. (1999). Working memory is more sensitive than declarative memory to the acute effects of corticosteroids: A dose-response study in humans. Behavioural Neuroscience, 113, 420-430.

Mahoney, C. R., Hirsch, E., Hasselquist, L., Lesher, L. L., \& Lieberman, H. R. (2007). The effects of movement and physical exertion on soldier vigilance. Aviation, Space, and Environmental Medicine, 78(5, Suppl.), 51-57.

Martin, K., Staiano, W., Menaspà, P., Hennessey, T., Marcora, S., Keegan, R., . . Rattray, B. (2016). Superior inhibitory control and resistance to mental fatigue in professional road cyclists. PLoS ONE, 11(7), e0159907.

Matsangas, P., McCauley, M. E., \& Becker, W. (2014). The effect of mild motion sickness and sopite syndrome on multitasking cognitive performance. Human Factors, 56, 1124-1135.

McEwen, B. S. (1999). Stress and hippocampal plasticity. Annual Review of Neuroscience, 22, 105-122.

Milanez, V. F., Pedro, R. E., Moreira, A., Boullosa, D. A., Salle-Neto, F., \& Nakamura, F. Y. (2011). The role of aerobic fitness on session rating of perceived exertion in futsal players. International Journal of Sports Physiology and Performance, 6, 358-366.

Milner, J. D., \& Wurtman, R. J. (1986). Catecholamine synthesis: Physiological coupling to precursor supply. Biochemical Pharmacology, 35, 875-881.

Milnik, A., Heck, A., Vogler, C., Heinze, H. J., de Quervain, D. J., \& Papassotiropoulos, A. (2012). Association of KIBRA with episodic and working memory: A meta-analysis. American Journal of Medical Genetics Part B: Neuropsychiatric Genetics, 159, 958-969.

Miu, A. C., Heilman, R. M., \& Miclea, M. (2009). Reduced heart rate variability and vagal tone in anxiety: Trait versus state, and the effects of autogenic training. Autonomic Neuroscience, 145, 99-103.

Mohajeri, M. H., Wittwer, J., Vargas, K., Hogan, E., Holmes, A., Rogers, P. J., . . Gibson, E. L. (2015). Chronic treatment with a tryptophan-rich protein hydrolysate improves emotional processing, mental energy levels and reaction time in middle-aged women. British Journal of Nutrition, 113, 350-365.

Morgan, C. A., III, Hazlett, G., Southwick, S., Rasmusson, A., \& Lieberman, H. R. (2009). Effect of carbohydrate administration on recovery from stress-induced deficits in cognitive function: A double-blind, placebo-controlled study of soldiers exposed to survival school stress. Military Medicine, 174(2), 132-138.

Morgan, C. A., III, Rasmusson, A., Pietrzak, R. H., Coric, V., \& Southwick, S. M. (2009). Relationships among plasma dehydroepiandrosterone and dehydroepiandrosterone sulfate, cortisol, symptoms of dissociation, and objective performance in humans exposed to underwater navigation stress. Biological Psychiatry, 66, 334-340. doi:10.1016/j.biopsych.2009.04.004

Morgan, C. A., III, Southwick, S., Hazlett, G., Rasmusson, A., Hoyt, G., Zimolo, Z., \& Charney, D. (2004). Relationships among plasma dehydroepiandrosterone sulfate and cortisol levels, symptoms of dissociation, and objective performance in humans exposed to acute stress. Archives of General Psychiatry, 61, 819-825. doi:10.1001/archpsyc.61.8.819

Morris, N., Toms, M., Easthope, Y., \& Biddulph, J. (1998). Mood and cognition in pregnant workers. Applied Ergonomics, 29, 377-381.

Murphy, S. E., Longhitano, C., Ayres, R. E., Cowen, P. J., \& Harmer, C. J. (2006). Tryptophan supplementation induces a positive bias in the processing of emotional material in healthy female volunteers. Psychopharmacology, 187, 121-130.

Nassef, A., Mahfouf, M., Linkens, D. A., Elsamahy, E., Roberts, A., Nickel, P., . . . Panoutsos, G. (2009, September 7-12). The assessment of heart rate variability (HRV) and task load index (TLI) as physiological markers for physical stress. Paper presented at the World Congress on Medical Physics and Biomedical Engineering, Munich, Germany.

Neri, D. F., Wiegmann, D., Stanny, R. R., Shappell, S. A., McCardie, A., \& McKay, D. L. (1995). The effects of tyrosine on cognitive performance during extended wakefulness. Aviation, Space, and Environmental Medicine, 66, 313-319.

Nibbeling, N., Oudejans, R. R., Ubink, E. M., \& Daanen, H. A. (2014). The effects of anxiety and exercise-induced fatigue on 
shooting accuracy and cognitive performance in infantry soldiers. Ergonomics, 57, 1366-1379. doi:10.1080/00140139.201 4.924572

O’Brien, C., Mahoney, C., Tharion, W. J., Sils, I. V., \& Castellani, J. W. (2007). Dietary tyrosine benefits cognitive and psychomotor performance during body cooling. Physiology \& Behaviour, 90, 301-307. doi:10.1016/j.physbeh.2006.09.027

Owen, G., Turley, H., \& Casey, A. (2004). The role of blood glucose availability and fatigue in the development of cognitive impairment during combat training. Aviation, Space, and Environmental Medicine, 75, 240-246.

Paul, M. A., MacLellan, M., \& Gray, G. (2005). Motion-sickness medications for aircrew: Impact on psychomotor performance. Aviation, Space, and Environmental Medicine, 76, 560-565.

Peters, J. C., \& Harper, A. E. (1985). Adaptation of rats to diets containing different levels of protein: Effects of food intake, plasma and brain amino acid concentrations and brain neurotransmitter metabolism. Journal of Nutrition, 115, 382-398.

Piccardi, L., Verde, P., Bianchini, F., Morgagni, F., Guariglia, C., \& Strollo, F. (2013). Mental rotation task in a pilot during and after pregnancy. Aviation, Space, and Environmental Medicine, 84, 1092-1094.

Piccardi, L., Verde, P., Bianchini, F., Morgagni, F., Guariglia, C., Strollo, F., \& Tomao, E. (2014). Deficits in visuo-spatial but not in topographical memory during pregnancy and the postpartum state in an expert military pilot: A case report. $B M C$ Research Notes, 7, Article 524. doi:10.1186/1756-0500-7-524

Popova, N. K., Ivanova, L. N., Amstislavskaya, T. G., Melidi, N. N., Naumenko, K. S., Maslova, L. N., \& Bulygina, V. V. (2001). Brain serotonin metabolism during water deprivation and hydration in rats. Neuroscience and Behavioral Physiology, 31, 327-332.

Prinsloo, G. E., Rauch, H. L., Lambert, M. I., Muench, F., Noakes, T. D., \& Derman, W. E. (2011). The effect of short duration heart rate variability (HRV) biofeedback on cognitive performance during laboratory induced cognitive stress. Applied Cognitive Psychology, 25, 792-801.

Pruessner, J. C., Baldwin, M. W., Dedovic, K., Renwick, R., Mahani, N. K., Lord, C., . . . Lupien, S. (2005). Self-esteem, locus of control, hippocampal volume, and cortisol regulation in young and old adulthood. NeuroImage, 28, 815-826.

Radakovic, S. S., Maric, J., Surbatovic, M., Radjen, S., Stefanova, E., Stankovic, N., \& Filipovic, N. (2007). Effects of acclimation on cognitive performance in soldiers during exertional heat stress. Military Medicine, 172, 133-136.

Reed, H. L., Reedy, K. R., Palinkas, L. A., Van Do, N., Finney, N. S., Case, H. S., . . Thomas, J. (2001). Impairment in cognitive and exercise performance during prolonged antarctic residence: Effect of thyroxine supplementation in the polar triiodothyronine syndrome. The Journal of Clinical Endocrinology and Metabolism, 86, 110-116. doi:10.1210/jcem.86.1.7092

Repperger, D., Jennings, T., Jacobson, J., Michel, N., Goodyear, C., \& Howeix, L. (1987). Study of neuromotor reaction times under the influence of thyrotropin-releasing hormone. Perceptual and Motor Skills, 65, 627-636. doi:10.2466/ pms.1987.65.2.627

Robbins, T. W. (2005). Chemistry of the mind: Neurochemical modulation of prefrontal cortical function. Journal of Comparative Neurology, 493, 140-146.

Rocha, K. K., Ribeiro, A. M., Rocha, K. C. F., Sousa, M. B. C., Albuquerque, F. S., Ribeiro, S., \& Silva, R. H. (2012). Improvement in physiological and psychological parameters after 6 months of yoga practice. Conscious Cognition, 21, 843-850.
Roebuck-Spencer, T. M., Reeves, D. L., Bleiberg, J., Cernich, A. N., Schwab, K., Ivins, B., . . Warden, D. (2008). Influence of demographics on computerized cognitive testing in a military sample. Military Psychology, 20, 187-203. doi:10.1080/08995600802118825

Rovira, E., Mackie, R. S., Clark, N., Squire, P. N., Hendricks, M. D., Pulido, A. M., \& Greenwood, P. M. (2016). A role for attention during wilderness navigation: Comparing effects of BDNF, KIBRA, and CHRNA4. Neuropsychology, 30, 709719. doi: $10.1037 /$ neu0000277

Salamone, J. D., Steinpreis, R. E., McCullough, L. D., Smith, P., Grebel, D., \& Mahan, K. (1991). Haloperidol and nucleus accumbens dopamine depletion suppress lever pressing for food but increase free food consumption in a novel food-choice procedure. Psychopharmacology, 104, 515-521.

Schmitt, J. A. J., Wingen, M., Ramaekers, J. G., Evers, E. A. T., \& Riedel, W. J. (2006). Serotonin and human cognitive performance. Current Pharmaceutical Design, 12, 2473-2486.

Seeman, T. E., Lusignolo, T. M., Albert, M., \& Berkman, L. (2001). Social relationships, social support, and patterns of cognitive aging in healthy, high-functioning older adults: MacArthur studies of successful aging. Health Psychology, 20, 243-255.

Selkirk, G. A., \& McLellan, T. M. (2001). Influence of aerobic fitness and body fatness on tolerance to uncompensable heat stress. Journal of Applied Physiology, 91, 2055-2063. doi:10.1152/jappl.2001.91.5.2055

Sherratt, S., \& Hersh, D. (2010). "You feel like family ..." Professional boundaries and social model aphasia groups. International Journal of Speech-Language Pathology, 12, 152-161. doi:10.3109/17549500903521806

Shia, R. M., Hagen, J. A., McIntire, L. K., Goodyear, C. D., Dykstra, L. N., \& Narayanan, L. (2015). Individual differences in biophysiological toughness: Sustaining working memory during physical exhaustion. Military Medicine, 180, 230-236. doi:10.7205/milmed-d-14-00363

Shukitt-Hale, B., Askew, E. W., \& Lieberman, H. R. (1997). Effects of 30 days of undernutrition on reaction time, moods, and symptoms. Physiology \& Behaviour, 62, 783-789. doi:10.1016/s0031-9384(97)00236-9

Silverman, M. N., \& Deuster, P. A. (2014). Biological mechanisms underlying the role of physical fitness in health and resilience. Interface Focus, 4(5), 20140040. doi:10.1098/rsfs.2014.0040

Singh, N., Nath, R., Mishra, N., \& Kohli, R. P. (1978). An experimental evaluation of anti-stress effects of "Geriforte" (an ayurvedic drug). Quarterly Journal of Crude Drug Research, 16, 125-136.

Sinyor, D., Schwartz, S. G., Peronnet, F., Brisson, G., \& Seraganian, P. (1983). Aerobic fitness level and reactivity to psychosocial stress: Physiological, biochemical, and subjective measures. Psychosomatic Medicine, 45, 205-217. doi:10.1097/00006842-198306000-00003

Smith, P. J., Blumenthal, J. A., Hoffman, B. M., Cooper, H., Strauman, T. A., Welsh-Bohmer, K., . . . Sherwood, A. (2010). Aerobic exercise and neurocognitive performance: A meta-analytic review of randomized controlled trials. Psychosomatic Medicine, 72, 239-252. doi:10.1097/PSY.0b013e3181d14633

Stellingwerff, T., \& Cox, G. R. (2014). Systematic review: Carbohydrate supplementation on exercise performance or capacity of varying durations. Applied Physiology, Nutrition, and Metabolism, 39, 998-1011.

Tajalizadekhoob, Y., Sharifi, F., Fakhrzadeh, H., Mirarefin, M., Ghaderpanahi, M., Badamchizade, Z., \& Azimipour, S. (2011). The effect of low-dose omega 3 fatty acids on the treatment of mild to moderate depression in the elderly: A double-blind, 
randomized, placebo-controlled study. European Archives of Psychiatry and Clinical Neuroscience, 261, 539-549.

Talukdar, T., Nikolaidis, A., Zwilling, C. E., Paul, E. J., Hillman, C. H., Cohen, N. J., . . . Barbey, A. K. (2018). Aerobic fitness explains individual differences in the functional brain connectome of healthy young adults. Cerebral Cortex, 28, 3600-3609. doi:10.1093/cercor/bhx232

Task Force of the European Society of Cardiology and the North American Society of Pacing and Electrophysiology. (1996). Heart rate variability: Standards of measurement, physiological interpretation and clinical use. Circulation, 93, 10431065.

Taylor, M. K., Markham, A. E., Reis, J. P., Padilla, G. A., Potterat, E. G., Drummond, S. P., \& Mujica-Parodi, L. R. (2008). Physical fitness influences stress reactions to extreme military training. Military Medicine, 173, 738-742. doi:10.7205/ MILMED.173.8.738

Tirre, W. C., \& Raouf, K. K. (1994). Gender differences in perceptual-motor performance. Aviation, Space, and Environmental Medicine, 65(5, Suppl.), 49-53.

Tomar, V. S., Singh, S. P., Singh, N., \& Kohli, R. P. (1984). Effect of Geriforte: An herbal compound drug on anoxic stress tolerance in rats. Probe, 24, 25-27.

Trousselard, M. (2009, July). Escape from a diving submarine simulator: Impacts of mindfulness differences on physiobiological responses and cognitive performances. Paper presented at the RTO Human Factors and Medicine Panel Symposium, Sofia, Bulgaria.

Van Cutsem, J., Marcora, S., De Pauw, K., Bailey, S., Meeusen, R., \& Roelands, B. (2017). The effects of mental fatigue on physical performance: A systematic review. Sports Medicine, 47, 1569-1588.

van der Linden, D., Frese, M., \& Meijman, T. F. (2003). Mental fatigue and the control of cognitive processes: Effects on perseveration and planning. Acta Psychologica, 113(1), 45-65.

van Dokkum, W., van Boxtel, L. B., van Dijk, M. J., Boer, L. C., \& van der Beek, E. J. (1996). Influence of a carbohydrate drink on performance of military personnel in NBC protective clothing. Aviation, Space, and Environmental Medicine, 67, 819-826.

Vasterling, J. J., Proctor, S. P., Amoroso, P., Kane, R., Heeren, T., \& White, R. F. (2006). Neuropsychological outcomes of army personnel following deployment to the Iraq war. Journal of the American Medical Association, 296, 519-529. doi:10.1001/jama.296.5.519

Verde, P., Boccia, M., Colangeli, S., Barbetti, S., Nori, R., Ferlazzo, F., . . Piccardi, L. (2016). Domain-specific interference tests on navigational working memory in military pilots. Aerospace Medicine and Human Performance, 87, 528-533. doi:10.3357/ amhp.4521.2016

Verde, P., Piccardi, L., Bianchini, F., Guariglia, C., Carrozzo, P., Morgagni, F., ... Tomao, E. (2015). Gender differences in navigational memory: Pilots vs. nonpilots. Aerospace Medicine and Human Performance, 86, 103-111. doi:10.3357/amhp.4024.2015

Vincent, A. S., Bleiberg, J., Yan, S., Ivins, B., Reeves, D. L., Schwab, K., . . W Warden, D. (2008). Reference data from the automated neuropsychological assessment metrics for use in traumatic brain injury in an active duty military sample. Military Medicine, 173, 836-852.

Vincent, A. S., Roebuck-Spencer, T., Gilliland, K., \& Schlegel, R. (2012). Automated neuropsychological assessment metrics (v4) traumatic brain injury battery: Military normative data. Military Medicine, 177, 256-269.

Vincent, A. S., Roebuck-Spencer, T., Lopez, M. S., Twillie, D. A., Logan, B. W., Grate, S. J., . . Gilliland, K. (2012). Effects of military deployment on cognitive functioning. Military Medicine, 177, 248-255.

Weerts, A. P., Pattyn, N., Van de Heyning, P. H., \& Wuyts, F. L. (2014). Evaluation of the effects of anti-motion sickness drugs on subjective sleepiness and cognitive performance of healthy males. Journal of Psychopharmacology, 28, 655-664.

Weiss, E. M., Kemmler, G., Deisenhammer, E. A., Fleischhacker, W. W., \& Delazer, M. (2003). Sex differences in cognitive functions. Personality and Individual Differences, 35, 863-875.

Wells, K. H., Wagner, H., Reich, L. N., \& Hardigan, P. C. (2009). Military readiness: An exploration of the relationship between marksmanship and visual acuity. Military Medicine, 174, 398-402.

Williams, D., Englund, C. E., Sucec, A. A., \& Overson, M. D. (1997). Effects of chemical protective clothing, exercise, and diphenhydramine on cognitive performance during sleep deprivation. Military Psychology, 9, 329-358. doi:10.1207/s15327876mp0904_5

Wilson, M. M., \& Morley, J. E. (2003). Impaired cognitive function and mental performance in mild dehydration. European Journal of Clinical Nutrition, 57, S24-S29.

Yanovich, R., Hadid, A., Erlich, T., Moran, D. S., \& Heled, Y. (2015). Physiological and cognitive military related performances after 10-kilometer march. Disaster and Military Medicine, 1, Article 6. doi:10.1186/2054-314x-1-6

Young, A. H., Sahakian, B. J., Robbins, T. W., \& Cowen, P. J. (1999). The effects of chronic administration of hydrocortisone on cognitive function in normal male volunteers. Psychopharmacology, 145, 260-266.

Kristy Martin is a postdoctoral fellow in the Research Institute for Sport and Exercise at the University of Canberra. She received her $\mathrm{PhD}$ in sport and exercise science from the University of Canberra in 2017.

Julien Périard is an associate professor in the Research Institute for Sport and Exercise at the University of Canberra. He received his $\mathrm{PhD}$ in exercise physiology from the University of Sydney in 2011.

Ben Rattray is an associate professor in the Research Institute for Sport and Exercise at the University of Canberra. He received his $\mathrm{PhD}$ in exercise physiology from the University of Sydney in 2009.

David B. Pyne is a professor in the Research Institute for Sport and Exercise at the University of Canberra. $\mathrm{He}$ received his $\mathrm{PhD}$ in biochemistry and molecular biology from the Australian National University in 1994.

Date received: July 27, 2018

Date accepted: March 13, 2019 